\title{
Early Childhood Development through an Integrated Program: Evidence from the Philippines*
}

\author{
Graeme Armecin ${ }^{\mathrm{a}}$, Jere R. Behrman ${ }^{\mathrm{b}}$, Paulita Duazo ${ }^{\mathrm{a}}$, Sharon Ghuman ${ }^{\mathrm{c}}$, Socorro Gultiano ${ }^{\mathrm{a}}$, \\ Elizabeth M. King ${ }^{\mathrm{d}}$ and Nanette Lee $\mathrm{e}^{\mathrm{a}, \mathrm{e}}$ \\ a Office of Population Studies, University of San Carlos, Cebu City, Philippines \\ ${ }^{\mathrm{b}}$ Economics Department, University of Pennsylvania, Philadelphia, PA \\ ${ }^{\mathrm{C}}$ The Population Council, New York, NY \\ dhe World Bank, Washington, DC \\ ${ }^{\mathrm{e}}$ University of North Carolina-Chapel Hill
}

Corresponding author: Elizabeth M. King, The World Bank, 1818 H Street, NW, Washington DC 20433; eking@worldbank.org

Keywords: early childhood development; program evaluation; Philippines

World Bank Policy Research Working Paper 3922, May 2006

The Impact Evaluation Series has been established in recognition of the importance of impact evaluation studies for World Bank operations and for development in general. The series serves as a vehicle for the dissemination of findings of those studies. Papers in this series are part of the Bank's Policy Research Working Paper Series. The papers carry the names of the authors and should be cited accordingly. The findings, interpretations, and conclusions expressed in this paper are entirely those of the authors. They do not necessarily represent the views of the International Bank for Reconstruction and Development/World Bank and its affiliated organizations, or those of the Executive Directors of the World Bank or the governments they represent.

* The authors are listed alphabetically to indicate that this paper is a product of a team project in which all the authors contributed in different ways. We thank the Early Childhood Development (ECD) Study Team at the Office of Population Studies (OPS) of the University of San Carlos for excellent support at all stages of the study; Dr. Lina Laigo and the Council for the Welfare of Children of the Philippine Government for enlightening discussions about government policy on ECD; Mike Argonza and the ECD Project Management Office for providing administrative data on program implementation; the World Bank ECD project managers for their encouragement and support; and Jun Pacificador for excellent input on sampling issues. We are also grateful for the financial support of various organizations: Grant R01-TW05604 ("Filipino Early Childhood Development: Longitudinal Analysis”) funded by the National Institutes of Health/Fogarty International Center, National Institute of Child Health and Human Development (NICHD), the Office of Behavioral and Social Science Research; the Global Development Network; the Department of Social Welfare and Development (DSWD) of the Government of the Philippines; the World Bank Research Support Budget (RPO 682-34); and a NICHD postdoctoral training fellowship for Ghuman (5 T32 HD07339) through the University of Michigan. An earlier version of this paper was presented at the Population Association of American (PAA) Annual Meetings in Philadelphia on April 1, 2005 and at the World Bank. We thank Susan Parker (discussant at the PAA) and participants at the PAA and World Bank presentations for helpful comments and input on the analysis. 


\section{Early Childhood Development through an Integrated Program: Evidence from the Philippines}

\section{ABSTRACT}

More attention and resources have been devoted in recent years to early childhood development (ECD) in low- and middle-income countries. Rigorous studies on the effectiveness of ECD-related programs for improving children's development in various dimensions in the developing world are scant. We evaluate an important ECD initiative of the Philippine government using longitudinal data collected over three years on a cohort of 6,693 children age 0-4 years at baseline in two "treatment” regions and a "control” region that did not receive the intervention. The initiative includes a wide range of health, nutrition, early education, and social services programs. We estimate its impact by using “intent-to-treat” difference-in-difference propensity score matching estimators to control for a variety of observed characteristics measured at the municipality, barangay, household, and child level and unobserved fixed characteristics, with differential impacts by age of children and duration of exposure to the program. There has been a significant improvement in the cognitive, social, motor and language development and in short-term nutritional status of children who reside in ECD program areas compared to those in non-program areas, particularly for those under age four at the end of the evaluation period. The proportions of children below age four with worms and diarrhea also have been lowered significantly in program compared to non-program areas, but there are effects in the opposite direction for older children so the overall impact on these two indicators is mixed. 


\section{Introduction}

In recent years, interest in early childhood development (ECD) in low- and middleincome countries has expanded considerably. High grade repetition in school, early dropout from school, and poor learning as well as poor health of youth and adults are being traced to malnutrition, disease, and neglect during early childhood. Accumulated evidence reveals associations between cognitive and psycho-social skills, nutrition and health status measured at young ages, on the one hand, and later educational attainment, earnings, and employment outcomes, on the other (e.g., Behrman and Rosenzweig 2004; Currie and Thomas 1999, Murnane, Willett and Levy 1995 and Neal and Johnson 1996 for the United States; Alderman, et al. 2001b, Alderman, Behrman and Hoddinott 2005, Alderman, Hoddinott and Kinsey 2006, Glewwe, Jacoby and King 2001, Glewwe and King 2001, Maluccio, et al. 2005, Martorell 1999 for developing countries). These life-cycle links suggest that a potentially effective way of alleviating poverty and engendering economic development is through policies that promote better development of cognitive, social, motor, and language skills and health and nutritional status among pre-school-age children.

Accordingly, governments in a number of countries, including the Philippines, have introduced ECD programs for enhancing the learning environments, improving nutrition and reducing disease for preschool children. To date, however, there are few rigorous evaluations of the effectiveness of ECD programs on child development that use longitudinal data and attempt to address possible bias in the estimates due to nonexperimental allocation of ECD services across a population. Most studies also do not examine many dimensions of development among young children or incorporate information on whether and how impacts differ depending on age and/or duration of exposure to the ECD intervention (Behrman, Cheng and Todd 2004, Gertler 2004, and Frankenberg, Suriastini and Thomas 2005 are recent exceptions).

In this paper, we estimate the impact of an important ECD initiative of the Philippine government. ${ }^{1}$ The overall aim of the program, initiated in the late 1990s, is to enable local governmental units (LGUs or municipalities) within three regions (comprising 13 provinces) to deliver a broader and better set of ECD-related services to pregnant women and children under age seven. Here we address the research question: Did this ECD program have a positive effect on children's well-being in the form of better cognitive, social, motor, language development and health and nutrition? We use longitudinal survey data collected in three rounds over three years on 6,693 children in randomly selected households. The surveys covered two "treatment" regions that received the ECD program and a "control” or comparison region that had not received the program. Program assignment was non-experimental and so we use difference-in-difference

\footnotetext{
${ }^{1}$ Although the program is being coordinated by the Department of Social Welfare and Development (DSWD), this government program is an interdepartmental program that also involves the Department of Education and the Department of Health.
} 
propensity score matching estimators to control for a variety of observed characteristics measured at the municipality, barangay ${ }^{2}$, household and child levels and unobserved fixed characteristics. We examine intent-to-treat impacts by child age, and because program implementation was not instantaneous, we also consider the length of exposure to the program. Our results indicate that the program has had important positive impacts on children's cognitive, motor, language and social development and short-run nutritional status, with some suggestion that duration of exposure increases the program impacts. The effects are particularly important for younger children (below four-years-old at the time of the evaluation).

\section{Evaluations of ECD programs}

There have been few systematic evaluations of ECD programs in developing countries that also use longitudinal data to control for the behavioral aspects of investments in preschool human capital; three are discussed later below. However, several programs in the United States that have been evaluated provide important lessons. The High/Scope Perry Preschool Study (Michigan) is a study of the effects of a high-quality preschool program for children born in poverty. It randomly assigned 123 children to program or noprogram control groups, and followed these children with respect to a variety of outcome measures from age 3 to age 41. From October through May each program year, program teachers conducted daily 21/2-hour classes for children on weekday mornings and made weekly 11/2-hour home visits to each mother and child on weekday afternoons. Program evaluations have found gains in children's readiness for school and their subsequent educational success, economic success in early adulthood (even home ownership), and reduced number of criminal arrests throughout their lives (Schweinhart and Weikart 1998; Belfield and others 2006). In addition to direct benefits to participants, the general public gains also in terms of higher tax revenues, lower criminal justice system expenditures, and lower welfare payments, repaying \$12.90 for every \$1 invested, easily outweighing program costs. In contrast to the Perry program, the Home Instruction Program for Preschool Youngsters (HIPPY) is exclusively parent-focused; it is a two-year home-based early education intervention program that aims to help parents with limited formal education prepare their four- and five-year-old children for school (Baker, Piotrkowski and Brooks-Gunn 1998). Para-professional trainers visited families bimonthly, providing teaching materials and parenting advice, and supplemented the visits in alternate weeks by group meetings with parents and paraprofessionals led by professional HIPPY program coordinators. Experimental evaluations of HIPPY have found positive impacts on cognitive test scores, at least over a two-to-three-year interval after the program. Experimental evaluations of two other programs (e.g., the Milwaukee and Abecedarin

\footnotetext{
${ }^{2}$ A barangay is the smallest political unit in the Philippines and is akin to a district or village.
} 
projects) documented modest positive effects on test scores that persisted through age 21 (Ramey, Campbell and Blair 1998).

Most of these evaluations of United States’ programs are based on relatively small samples and it is therefore difficult to generalize results based on the experiences at a single program site to a larger population of interest. The main exception is the nonexperimental evaluation of the Head Start program that controlled for mother- and childspecific unobservables and showed that the program had positive impacts on test scores, immunization rates and lowered grade repetition, primarily among whites and Hispanics (Currie and Thomas 1995). Due to factors such as lower program expenditure per child, less well-trained service providers, and children that are more malnourished, it is not clear that the positive impacts observed in the United States' programs will be observed also in poorer countries.

The limited, though growing, evidence to date suggests that ECD programs have been successful in some developing country settings. Bolivia’s PIDI (Proyecto Integral de Desarrollo Infantil) provides 70 percent of recommended nutrient inputs and systematic learning environments for poor children aged 6-72 months in urban areas. Behrman, Cheng and Todd (2004) compare children in the program for short (less than two months) and longer durations in the absence of satisfactory baseline and nonrandom treatment (partly due to household choices and partly due to PIDI center choices). Propensity score matching methods are used to control for any bias due to the selection into PIDI that was not random in nature. The authors find that the program had positive effects on children's growth and psycho-social development, and estimate that these effects mean gains in lifetime earnings suggestive of earnings-benefits to program-cost ratios of 1.7 to 3.7. For Indonesia, Frankenberg, Suriastini and Thomas (2005) find that after controlling for community-level unobservables using fixed effects, the placement of midwives in villages is related to substantial positive effects on height-for-age (about one third of a standard deviation increase) among children one to four years old.

Two evaluations of the Mexico's Education, Health, and Nutrition Program (PROGRESA) have found positive effects. Gertler (2004) found that newborns in treatment communities were 25.3 percent less likely to be reported as ill in the month prior to the survey than newborns in control communities; similarly, children under four were 22.3 percent less likely to be ill than controls. In addition, treatment children were 8.6 percent less likely to be stunted (though this difference is not statistically significant) and 25.5 percent less likely to be anemic. Like Gertler, Behrman and Hoddinott (2005) found that nutritional supplements for children 12-36 months in rural communities produced an increase of about a one-sixth in mean growth per year for these children and a lower probability of stunting (controlling in their estimates for unobserved heterogeneity using child fixed-effects). They estimate that the long-term consequences of this improvement in child health are non-trivial, and that its direct impact on adult height alone could result in a 2.9 percent increase in lifetime earnings. 


\section{About the Philippine ECD program}

In 1999, the Philippine Government launched a five-year ECD Project in three southern regions encompassing thirteen provinces and about 2.2 million households Region 6 (Western Visayas), Region 7 (Central Visayas), and Region 12 (Central Mindanao). ${ }^{3}$ A few years later, in 2002, the project became part of a broader governmental program that was formally adopted through the Early Childhood Care and Development (ECCD) Act (Republic Act 8980). The program's overarching goal is to improve the survival and developmental potential of children, particularly those who are most vulnerable and disadvantaged by: 1) minimizing the health risks to very young children; 2) contributing to the knowledge of parents and the community about child development and encouraging their active involvement; 3 ) advocating for child-friendly policy and legislation; 4) improving the ability and attitude of child-related service providers; and 5) mobilizing resources and establishing viable financing mechanisms for ECD projects. The program spans a wide range of health, nutrition, early education, and social services programs.

Health and ECD-related service providers and facilities are important conduits for the implementation of the program. Public health services in the Philippines have a hierarchical structure containing provincial hospitals, municipality rural health units (staffed by doctors, nurses and midwives), and at the barangay level, health stations that are staffed by midwives and other barangay-level health workers who assist them. The main function of the barangay health station is to provide low cost or free preventative and curative primary health services to pregnant women and children, with a referral system for more complicated cases to municipality and provincial hospitals. In many cases, the project has upgraded and improved the facilities and amenities available to existing service providers (e.g., midwives, barangay health workers and nutrition scholars, and day care workers) to accomplish their duties.

In contrast to some other ECD programs (e.g., the Bolivian PIDI program), the Philippine project did not introduce new services; rather, its innovation is to adopt an integrated, multi-sectoral approach to delivering a combination of services that include center-based (e.g., day care centers, pre-schools, health stations) and home-based (e.g., family day care programs, and home visits by health workers) interventions. To link the center-based and home-based services, a new service provider, the Child Development Worker (CDW), was placed in all program areas. The CDWs have the task of complementing the roles of midwives and health workers in providing food and nutritional supplements and monitoring children's health status, and are responsible for communitybased parent education about ECD. The program also set out to improve the national child

\footnotetext{
${ }^{3}$ The project was viewed as a means to help attain the country's human development goals and to reduce poverty; an instrument to meet the government's commitment to the international Convention on the Rights of Children of which the Philippines is a signatory; and a pilot effort for testing ECD structures and delivery systems.
} 
surveillance and referral systems, expand community participation and local ownership to ensure sustainability, and establish the Council for the Welfare of Children (CWC) which functions as the national ECCD Coordinating Council under the Office of the President, with counterparts at the provincial, municipal and barangay levels. ${ }^{4}$ Appendix A provides more detail on the specific components of the program.

The ECD program assignment to municipalities or LGU's was a process that took several steps. ${ }^{5}$ First, municipalities that were deemed "high risk or needy" were identified on the basis of several indicators such as infant mortality rates, maternal mortality rates, low birth weight, child malnutrition, and schooling attainment among children and women. Second, an information campaign was launched to enlist the participation and cooperation of city and town mayors and other local health officials (planning and development officers, health officers, barangay captains, NGO representatives) as program partners. Within the Philippines' decentralized governmental system, while policy-making on ECD is the primary task of the national ECCD Council, LGU's are responsible for providing basic ECD services, supporting the organization of parent cooperatives to initiate programs, financing the salaries of service providers, and providing counterpart funds for local ECD councils. ${ }^{6}$ Local officials therefore essentially decide the menu of ECD services to be implemented in each LGU. Accordingly, in the propensity score matching estimates we incorporate baseline characteristics of barangay and LGU leaders.

Table 1 shows the functions and duties of service providers at the latest available survey round by whether they work in a program area. Midwives in program areas are significantly more likely than those in non-program areas to undertake critical functions including examining patients, diagnosing ailments, making referrals, educating and talking to clients, monitoring new cases, following up via home visits, and providing nutrition counseling. Barangay health workers in program areas are significantly more likely to engage in home visits and dispense nutritional supplements. Daycare providers in program areas are also significantly more likely to make referrals, educate and talk to clients, teach parents about ECD and child health, engage in home and follow-up visits, take weight and health measurements of children and conduct infant feedings. About 40 to 50 percent of

\footnotetext{
${ }^{4}$ The Act provides for the creation of Provincial and City/Municipal ECCD Coordinating Committees, as well as the Barangay Council for the Protection of Children (BCPC) which functions as the Barangay ECCD Coordinating Committee.

${ }^{5}$ The project areas were divided into focus-targeted areas and self-targeted areas. The focus-targeted municipalities were expected to take advantage of the project by the year 2003 through a phased-in schedule of inscription into the project. The self-targeted municipalities were invited to participate at any time during the project's duration with the provision that they meet DSWD-specified conditions about ECD services.

${ }^{6}$ With respect to funding, the national agencies are expected to provide counterpart resources for the establishment and expansion of ECCD programs in poor and disadvantaged communities. These funds are supposed to be available through the Municipal Development Fund. The ECCD Act explicitly allows resource mobilization from intergovernmental donors and financial institutions for the support of poor areas. See Furtado (2001) for a critical assessment of the impact of decentralization in the Philippines on public health.
} 
Child Development Workers educate and talk to parents or children, 57 percent conduct infant feedings, and nearly 80 percent engage in home visits and growth monitoring. These results show an intensification of the provision of a range of crucial health and ECDrelated services for both young children and parents in program areas.

Table 1. Functions of Service Providers by Type of Provider and ECD Program Area, Philippines ECD Study (Round 3)

\begin{tabular}{|c|c|c|c|c|c|c|c|}
\hline \multirow{2}{*}{$\begin{array}{l}\text { Provider Type: } \\
\text { Program (P) or non- } \\
\text { program (NP) area: } \\
\text { Functions: }\end{array}$} & \multicolumn{2}{|c|}{$\begin{array}{l}\text { Rural Health } \\
\text { Midwife }\end{array}$} & \multicolumn{2}{|c|}{$\begin{array}{c}\text { Barangay } \\
\text { Health Worker }\end{array}$} & \multicolumn{2}{|c|}{$\begin{array}{l}\text { Day Care } \\
\text { Worker }\end{array}$} & \multirow{2}{*}{$\begin{array}{c}\text { Child } \\
\begin{array}{c}\text { Developmen } \\
\text { Worker }^{\mathrm{a}}\end{array} \\
\mathrm{P}\end{array}$} \\
\hline & $\mathrm{P}$ & NP & $\mathrm{P}$ & NP & $\mathrm{P}$ & NP & \\
\hline Examine patients & 95.5 & $81.7^{*}$ & 3.1 & 6.1 & n.a. & n.a. & n.a. \\
\hline Provide diagnosis & 30.5 & $12.0^{*}$ & 0.24 & 0 & n.a. & n.a. & n.a. \\
\hline Dispense medicines & 88.7 & 91.7 & 15.4 & 16.5 & 0 & 0 & 2.8 \\
\hline Make referrals & 57.1 & $36.7^{*}$ & 14.2 & 10.8 & 7.7 & $0 *$ & 11.1 \\
\hline $\begin{array}{l}\text { Educate or talk to } \\
\text { clients }\end{array}$ & 67.2 & $36.7^{*}$ & 19.5 & 15.4 & 54.1 & $35.0^{*}$ & 48.2 \\
\hline Teach parents & n.a. & n.a. & n.a. & n.a. & 32.8 & $2.0^{*}$ & 42.5 \\
\hline Monitor new cases & 43.5 & $19.3^{*}$ & 3.9 & 4.7 & n.a. & n.a. & n.a. \\
\hline $\begin{array}{l}\text { Home visits and } \\
\text { follow-up }\end{array}$ & 69.0 & $52.3^{*}$ & 86.1 & $78.5^{*}$ & 71.4 & $37.0 *$ & 78.7 \\
\hline $\begin{array}{l}\text { Take weight and height } \\
\text { measurements }\end{array}$ & 93.8 & 94.5 & 93.8 & 93.2 & 47.3 & $4.0^{*}$ & 77.8 \\
\hline Nutrition counseling & 68.4 & $35.8^{*}$ & 16.8 & 11.8 & n.a. & n.a. & n.a. \\
\hline Dispense supplements & 91.5 & 86.2 & 64.2 & $42.0^{*}$ & 2.9 & 1.0 & 5.6 \\
\hline Conduct infant feedings & n.a. & n.a. & n.a. & n.a. & 44.4 & $19.0^{*}$ & 56.5 \\
\hline $\mathrm{N}$ & 176 & 109 & 416 & 279 & 207 & 100 & 108 \\
\hline
\end{tabular}

a. Child Development Workers are found in ECD program areas only (see text).

n.a. not applicable to this provider type.

* Mean is significantly different between program and non-program children at the .05 level.

Source: 2003/2004 Early Childhood Development Provider Survey.

Table 2 shows that by the third survey round, midwives and day care providers in the program areas are substantially more likely than providers in non-program regions to have received training in topics such as parent education, management of child illness, and growth monitoring; two thirds of child development workers received training on educating parents about child health. Although barangay health workers were less likely to receive training than other types of providers, they are more likely to receive health and ECD-related training if they work in a program barangay than in a non-program barangay. 
Table 2. Percentage of Service Providers who Received ECD-Related Training by Type of Training and ECD Program Area, Philippines ECD Study (Round 3)

\begin{tabular}{|c|c|c|c|c|c|c|c|}
\hline \multirow{3}{*}{\begin{tabular}{l}
\multicolumn{1}{c}{ Provider Type: } \\
Program (P) or non- \\
program (NP) region: \\
Parent education
\end{tabular}} & \multicolumn{2}{|c|}{$\begin{array}{l}\text { Rural Health } \\
\text { Midwife }\end{array}$} & \multicolumn{2}{|c|}{$\begin{array}{c}\text { Barangay Health } \\
\text { Worker }\end{array}$} & \multicolumn{2}{|c|}{$\begin{array}{l}\text { Day Care } \\
\text { Worker }\end{array}$} & \multirow{2}{*}{$\begin{array}{c}\text { Child } \\
\begin{array}{c}\text { Development } \\
\text { Worker }^{\mathrm{a}}\end{array} \\
\mathrm{P}\end{array}$} \\
\hline & $\mathrm{P}$ & NP & $\mathrm{P}$ & NP & $\mathrm{P}$ & NP & \\
\hline & 36.3 & 1.0 & 4.9 & 0 & 83.7 & 0 & 61.5 \\
\hline $\begin{array}{l}\text { Management of Child } \\
\text { illness }\end{array}$ & 52.5 & 4.2 & 4.9 & 1.7 & n.a. & n.a. & 1.8 \\
\hline Growth monitoring & 45.3 & 10.4 & 16.7 & 0 & 3.4 & 0 & 0.9 \\
\hline Health Care Service & 13.4 & 3.1 & & & & & 1.8 \\
\hline Delivery & & & 6.5 & 1.7 & 1.0 & 1.1 & \\
\hline $\mathrm{N}$ & 179 & 96 & 306 & 174 & 208 & 92 & 109 \\
\hline
\end{tabular}

a. Child development workers are found in ECD program areas only (see text).

n.a. not applicable to this provider type.

Source: OPS (2005).

The program has also significantly increased several primary health care and other services designed to promote ECD. Table 3 shows the percentage of municipalities that had functioning elements of various ECD-related services in the first round and the latest available round depending on whether they are in program or non-program regions. This table omits many of the programs listed in Appendix A, because these services were present in all municipalities in Round 1 and Round 3, but received important upgrades of equipment, training and supplies in program areas. Between the baseline and latest round, there is a clear positive trend in the spread of functioning feeding programs, parent education programs, and home-based day care in program areas that is either not observed or not as strong in non-program areas.

Table 3. Percentage of Municipalities with ECD-related Programs by Program Regions and Survey Round, Philippines ECD Study

\begin{tabular}{lcc}
\hline Type of Program & Program Areas & Non-Program Areas \\
\hline Feeding Programs & 32.3 & \\
Round 1 & 69.4 & 28.1 \\
Round 3 & & 38.6 \\
Parent Education/Effectiveness Seminars & 77.4 & \\
Round 1 & 100.0 & 68.4 \\
Round 3 & & 63.2 \\
Home-Based Day Care & 16.1 & \\
Round 1 & 44.4 & 8.8 \\
Round 3 & & 0 \\
Number of Municipalities & 31 & 57 \\
Round 1 & 36 & 57 \\
Round 3 & & \\
\hline Source: Calatedbasedon da & & \\
\hline
\end{tabular}

Source: Calculated based on data shown in OPS (2005). 


\section{Data}

\section{Sampling design}

The overall evaluation design includes a series of household and child surveys, beginning with a baseline survey in 2001. Three surveys of the same sample of about 5,000 households from two of the program regions (Region 6 and 7) and a non-program region (Region 8) have been completed. ${ }^{7}$ In each round, data were collected also from local officials and ECD service providers. The sampling strategy involved stratifying the barangays in each province into (1) pilot barangays that were supposed to have participated in a pilot phase launched in $1998,{ }^{8}$ (2) program or target barangays in Phase 1 of the project, and (3) non-program barangays or non-targeted barangays in the (pilot and Phase 1) program and non-program municipalities in the region. ${ }^{9}$ In each program region, five pilot and five non-program barangays were randomly chosen, while the remaining barangays were drawn at random from the program barangays. In Region 8, sample barangays were randomly chosen from all barangays, with the number of barangays chosen proportionate to the total number of barangays in each province. In each sample barangay, an average of 24 eligible households (i.e., households with 0-6 year-old children or households with pregnant women) in Regions 6 and 7 and 14 households in Region 8 were selected. The overall response rate was high at 96 percent. During the baseline survey, 7,922 children aged 0-4 were selected to be followed up in the succeeding rounds; children aged 5-6 years old were not included for the evaluation sample because they were too old to be exposed much to the program. All estimates are weighted to account for the sampling scheme.

Of the original cohort of 7,922 children age 0-4, 86 percent (or 6,774 children) were successfully followed up in the same barangays in the first follow-up survey in 2002 (Round 2) and the second follow-up survey in 2003 (Round 3) (see Table B.1). For cost reasons, we only tracked and attempted to interview children in households whose members migrated to another barangay within the same province (399 children or 5 percent of the sample). Out-migration to a non-sample barangay outside the sample municipality or province was the main reason for attrition (552 children). Another 197 children were lost due to deaths, refusals or incomplete interviews. The overall attrition rate by Round 3 was 9 percent (or 749/7922). This attrition rate is comparable to other longitudinal surveys in developing countries (e.g., Alderman, et al. 2001a) though higher

\footnotetext{
${ }^{7}$ The baseline survey was conducted in April-August 2001; the first follow-up survey was fielded in September-November 2002, and the second follow-up in September -November 2003.

${ }^{8}$ Although the pilot barangays were supposed to have received initial ECD project inputs prior to the data collection phase of this study, these project inputs were delayed. As discussed in the section on Data and Methodology, we exclude from our estimation sample all barangays that received project inputs prior to the baseline Round 1 data collection.

${ }^{9}$ This classification was based on a list of program barangays provided by the Project Management Office (PMO) and verified with the DSWD field offices in the respective areas.
} 
than other surveys where respondents are tracked and re-interviewed irrespective of where they move within the sample area (e.g., as in the Indonesia Family Life Survey, see Thomas, Frankenberg and Smith 2001).

We include only the children who were successfully followed up in the same barangays in Rounds 2 and 3 in the analysis because those who were in Round 1 but not in the two other rounds (with the exception of the few refusals or incomplete interviews) died or experienced changes in treatment status when they moved. Table 4 shows the sample sizes for children who remained in the same sample barangay for all three surveys and were not missing critical data in Round 3. This group totals 6,693 children. The sample in non-program areas thus includes: 1) children living in barangays in regions 6 and 7 who did not receive the program by Round 3 and 2) all children who reside in region 8 . As can be seen from Table 4, very few sample children residing in regions 6 and 7 were not living in program barangays by Round 3. Thus, our measure of treatment is essentially (though not identical to) whether a child resides in regions 6 or 7 .

Table 4. Sample Sizes for Program and Non-Program Children by Region, Philippines ECD Study

\begin{tabular}{lr}
\hline Region and Program or Non-program Areas & $\mathrm{N}$ \\
\hline Program Areas & \\
Region 6 & 1,682 \\
Region 7 & 2,458 \\
Total & 4,140 \\
Non-Program Areas & \\
Region 6 & 145 \\
Region 7 & 49 \\
Total & 194 \\
Region 8 & 2,359 \\
Total & 6,693 \\
\hline
\end{tabular}

For the purposes of this evaluation, a central question is whether attrition is selective with respect to treatment status. Several studies on the U.S. and developing countries show that non-random attrition generally does not have a significant effect on multivariate estimates of socioeconomic status, including estimates of how family background affects a child's nutritional status and cognitive, social, motor and language development (see Fitzgerald, Gottschalk and Moffitt 1998 and Alderman et al 2001a for reviews and further discussion).

Appendix Table B.2 gives estimates of the relationship between remaining in the same sample barangays for all three survey rounds and the treatment status, baseline family background variables and child's age, and interactions between these variables and treatment status. The results indicate that children in non-program areas are significantly less likely to remain in the sample. The interactions with treatment status are significant in 
a few cases and when taken as a set, they are jointly significantly different from zero. For example, not having a father in the household has a significantly larger positive association with attrition in program areas. Living in a barangay with a paved road is significantly more likely to be positively related to migrating out of a non-program barangay, perhaps reflecting the fact that out-migration is facilitated by the easy crossing to Manila. However, we note that interpretation of these interaction terms is complicated since they may reflect unobserved behavioral mechanisms. Since a number of family background variables have differential effects on attrition by treatment status, there is a need to correct for possible sources of bias. To correct for attrition on observables, we re-weighted the observations for attrition using predicted values from the regression shown in Table B.2 as in Behrman, Parker and Todd (2006), which provides a formal discussion of this procedure.

\section{Measures of early child development}

Table 5 presents means for different ECD indicators in Rounds 1 and 3 by whether the child resides in an area that received the ECD program.

Cognitive, social, motor and language development. The project collected information on seven domains of child development using an instrument developed for the evaluation by a team of Philippine experts. ${ }^{10}$ The seven domains are: 1) Gross motor skills - movements of the entire body, trunk and/or limbs (e.g., sitting, walking, climbing and jumping); 2) Fine motor skills_-movements of the hands and fingers (e.g., reaching, grasping, and writing); 3) Receptive language — understanding of verbal communication; 4) Expressive language - use of language to convey thoughts and needs; 5) Cognitive development - ability to think, reason, understand concepts and solve problems, as well as early literacy and numeracy skills; 6) Social-emotional development-ability to respond in an age- and culturally appropriate manner to social situations and interpersonal relationships; and 7) Self help_-ability to perform daily living activities such as feeding, dressing and toileting. Each domain contains between nine and 22 items that are developmentally sequenced to increase in the degree of difficulty of tasks. Within a domain, each item takes a value of one for presence of a skill and zero if not present. The sums of the raw scores are scaled within a series of age intervals to reflect a distribution with a mean of 10 and a standard deviation of three. ${ }^{11}$

\footnotetext{
${ }^{10}$ The Revised ECD Checklist (REC) was developed by a team of experts led by Drs. Lourdes Ledesma and Elizabeth Ventura of the Department of Psychology at the University of the Philippines, Diliman.

${ }^{11}$ The scores are normed, controlling for age and sex, by comparing them with the scores for a sample of 10,915 Filipino children age zero to six years old drawn from regions 6, 7, 8 along with Regions 3 and 12 (Central Luzon and Central Mindanao). The instrument was applied to all children except those with serious health problems (e.g., poorly controlled seizures), debilitating anomalies (e.g., meningocoeles and cerebral palsy) or those with special needs (e.g., autism).
} 
Table 5. Means and Percentages for Selected ECD Indicators by Survey Round and Treatment Status, Philippines ECD Study

\begin{tabular}{|c|c|c|c|c|c|c|}
\hline \multirow[b]{2}{*}{ Indicator/Region } & \multicolumn{3}{|c|}{ Round 1} & \multicolumn{3}{|c|}{ Round 3} \\
\hline & Program & $\begin{array}{c}\text { Non- } \\
\text { program }\end{array}$ & Total & Program & $\begin{array}{l}\text { Non- } \\
\text { program }\end{array}$ & Total \\
\hline \multicolumn{7}{|c|}{ 1. Cognitive, Social, Motor and Language Development } \\
\hline \multirow[t]{2}{*}{ Gross motor skills } & -.197 & -.296 & -.223 & .091 & $-.329 *$ & -.021 \\
\hline & {$[.043]$} & {$[.053]$} & {$[.034]$} & [.029] & [.081] & {$[.029]$} \\
\hline \multirow[t]{2}{*}{ Fine motor skills } & -.237 & -.134 & -.217 & -.491 & -.629 & -.526 \\
\hline & {$[.041]$} & {$[.080]$} & {$[.034]$} & {$[.052]$} & {$[.052]$} & {$[.040]$} \\
\hline \multirow{2}{*}{$\begin{array}{l}\text { Expressive } \\
\text { language }\end{array}$} & -.255 & -.277 & -.260 & -.012 & $-.416^{*}$ & -.116 \\
\hline & {$[.034]$} & {$[.055]$} & {$[.029]$} & {$[.024]$} & {$[.061]$} & {$[.024]$} \\
\hline \multirow{2}{*}{$\begin{array}{l}\text { Receptive } \\
\text { language }\end{array}$} & -.209 & -.133 & -.192 & -.046 & $-.444^{*}$ & -.149 \\
\hline & {$[.040]$} & {$[.085]$} & {$[.031]$} & {$[.050]$} & {$[.103]$} & {$[.049]$} \\
\hline \multirow[t]{2}{*}{ Cognitive } & -.480 & $-.322 *$ & -.443 & -.653 & $-.906 *$ & -.720 \\
\hline & {$[.031]$} & {$[.047]$} & {$[.025]$} & {$[.042]$} & {$[.064]$} & {$[.034]$} \\
\hline \multirow[t]{2}{*}{ Self-help } & .003 & -.135 & -.027 & .147 & $-.038 *$ & .090 \\
\hline & {$[.032]$} & {$[.112]$} & [.038] & {$[.038]$} & {$[.068]$} & {$[.033]$} \\
\hline \multirow[t]{2}{*}{ Social-emotional } & .108 & .034 & .084 & .087 & $-.237 *$ & -.002 \\
\hline & {$[.046]$} & [.099] & {$[.038]$} & {$[.051]$} & {$[.092]$} & {$[.048]$} \\
\hline \multicolumn{7}{|l|}{ 2. Anthropometrics } \\
\hline \multirow[t]{2}{*}{ Height-for-age Z } & -1.57 & -1.67 & -1.59 & -1.79 & -1.88 & -1.81 \\
\hline & {$[.036]$} & {$[.045]$} & {$[.028]$} & [.037] & {$[.047]$} & {$[.030]$} \\
\hline \multirow{2}{*}{$\begin{array}{l}\text { Weight-for-height } \\
\text { Z }\end{array}$} & -0.638 & -0.696 & -0.647 & -0.355 & $-.526^{*}$ & -0.399 \\
\hline & {$[.038]$} & {$[.056]$} & {$[.031]$} & {$[.044]$} & {$[.034]$} & {$[.033]$} \\
\hline \multirow[t]{2}{*}{ Percentage stunted } & 34.9 & 38.7 & 35.7 & 43.4 & 48.6 & 44.5 \\
\hline & {$[.014]$} & {$[.021]$} & {$[.011]$} & {$[.016]$} & {$[.024]$} & {$[.013]$} \\
\hline \multirow[t]{2}{*}{ Percentage wasted } & 7.4 & 6.1 & 7.1 & 2.4 & 2.5 & 2.4 \\
\hline & {$[.009]$} & {$[.012]$} & {$[.007]$} & {$[.003]$} & {$[.005]$} & {$[.003]$} \\
\hline \multirow[t]{2}{*}{ 3. Worms } & 25.8 & $33.7^{*}$ & 27.5 & 29.6 & 33.9 & 30.4 \\
\hline & {$[.018]$} & {$[.024]$} & {$[.014]$} & {$[.021]$} & {$[.034]$} & {$[.017]$} \\
\hline \multirow{2}{*}{$\begin{array}{l}\text { 4. Diarrhea (in } \\
\text { past two weeks) }\end{array}$} & 10.1 & 9.9 & 10.1 & 2.8 & 4.3 & 3.1 \\
\hline & {$[.013]$} & {$[.015]$} & {$[.010]$} & {$[.005]$} & {$[.009]$} & {$[.005]$} \\
\hline \multirow{2}{*}{$\begin{array}{l}\text { 5. Hemoglobin } \\
\text { (gms/deciliter) }\end{array}$} & 10.9 & 10.8 & 10.9 & 11.3 & $11.6^{*}$ & 11.4 \\
\hline & {$[.055]$} & {$[.055]$} & {$[.042]$} & [.059] & {$[.066]$} & {$[.046]$} \\
\hline \multirow[t]{2}{*}{ Percentage anemic } & 45.7 & 48.5 & 46.3 & 41 & $31.0 *$ & 38.2 \\
\hline & {$[.016]$} & {$[.022]$} & {$[.013]$} & [.019] & {$[.034]$} & {$[.015]$} \\
\hline
\end{tabular}

Standard errors are in brackets. *Mean is significantly different between program and non-program children at the .05 level. 
In the analysis, we express the scaled scores in each of the seven domains relative to a sample of "healthy" children by calculating Z-values that are measured as the number of standard deviations below the reference sub-sample mean. The reference group is children who reside in households where the father and mother have 12 years of schooling or higher, the household falls in the upper quartile of the income distribution, the house has cement walls and an iron roof. In the first round, the $\mathrm{Z}$ values range from about one fifth to four tenths of a standard deviation below the reference mean for five of the seven domains.

Anthropometric indicators of nutrition and health status. The project collected children's weight and height which were used to calculate Z scores for height-for-age and weight-for-height (i.e., the number of standard deviations below or above the widely-used National Center for Health Statistics standard). Z scores that are more than two standard deviations below the reference population medians for height-for-age and weight-forheight, respectively, are considered to be indicative of stunting and wasting (World Health Organization, 1995). At the baseline, the mean $\mathrm{Z}$ scores in Table 5 indicate significant deficits below the reference population median that are, on average, over one and a half standard deviations lower for height-for-age and about three-fifths of a standard deviation for weight-for-height. Thirty-six percent and 7 percent of the children in the sample were stunted and wasted, respectively. While anthropometric Z scores are not significantly different between program and non-program children at the baseline, by Round 3, the $\mathrm{Z}$ scores for weight-for-height among program children are about one-fifth of a standard deviation higher.

Worms. We measure the percentage of children who had worms six months before the survey. Global estimates indicate that 1.3 billion people carry hookworm (Necator americanus, Ancylostoma duodenale), 1.3 billion are infected with roundworm (Ascaris lumbricoides), 900 million with whipworm (Trichuris trichura), and 200 million with schistosomiasis (Bundy, et al. 2001, Miguel and Kremer 2004). Most of those infected are school-age or pre-school age children in developing countries. Children with light helminth infections are often asymptomatic, but more severe worm infections can suffer from iron deficiency anemia, protein energy malnutrition, stunting, wasting, listlessness, and abdominal pain. Schistosomiasis can have more severe clinical consequences, including hepatosplenomegaly (enlargement of the liver and spleen). In a recent study, Miguel and Kremer (2004) find that treatment for worms reduced primary school absenteeism by 25 percent in Kenya. In our sample, about 28 percent of children had intestinal worms in Round 1.

Diarrhea. As with worms, diarrhea generally afflicts children below age five in developing countries. Among low- and middle-income countries where 90 percent of all deaths under age five occur, about 20 percent of such deaths are attributable to diarrheal diseases (Black, Morris and Bryce 2003). Diarrhea, which is often accompanied by a loss of appetite, fever and vomiting, can lead to malnutrition and longer term growth 
retardation among children (Martorell and Ho 1984). In Rounds 1 and 3, 10 and 3 percent of children had diarrhea two weeks prior to the survey.

Hemoglobin count and anemia. The study measured the hemoglobin levels from blood samples taken from children six months of age or older. ${ }^{12} \mathrm{~A}$ hemoglobin level below the cut-off of 11.0 grams per 100 milliliters for children age six to 59 months of age is considered to be indicative of iron deficiency related anemia (World Health Organization 2001). Iron deficiency is shown to have deleterious consequences for children's cognitive and motor functioning and may impair their ability to resist and successfully recover from infections (e.g., Grantham-McGregor and Ani 2001, Oppenheimer 2001; Pollitt 1997). Forty-six percent of our sample children had readings below 11 grams per 100 milliliters in Round 1, with the mean level of hemoglobin for children of 11.4 in the latest round.

\section{Methodology}

We want to estimate the impact of the program (P) on a number of outcomes (Y) such as the quantitative goals of the ECD project. The estimates that we present, both the preferred difference-in-difference propensity score matching estimates and the differencein-difference estimates, are "intent to treat" effects (that is, the impact of having the ECD program, on average, for all children in a given age range in the barangay, whether or not all of the children in the barangay actually received treatment). Estimating the impact of the program on the children who actually were treated (that is, the "treatment-on-thetreated”) is conceptually complex and difficult to implement because: (1) the program has several components, some new (such as child minding and the Child Development Workers) and some being improvements on already existing services such as growth monitoring and micronutrient supplementation; (2) the delivery of many of the program components is not centralized, so actual treatment under various components is difficult to ascertain and model; and (3) information campaigns about ECD in the community as well as home-based visits are an important aspect of the program mechanisms. In all, program impact is not likely to depend on service utilization in ways that may be true for programs that offer a single centralized service. ${ }^{13}$

\footnotetext{
${ }^{12}$ Children less than age six months are generally not included because among full-term infants the risk of iron deficiency in this age range is relatively low due to adequate iron provisions from the perinatal period (World Health Organization 2001). Hemoglobin levels were determined by diluting blood samples with a cyanmethemoglobin reagent in a spectrophotometer and using the proportional relationship of the absorbance of the reagent with the concentration of hemoglobin to determine the latter quantity. This method is one of two generally recommended as best for assessing hemoglobin levels in surveys (World Health Organization, 2001).

${ }^{13}$ Moreover, for some of the new components of the program such as child minding, utilization rates were far too low to allow us to use them in the analysis. Several other program components such as receiving home visits from barangay health workers, immunization, or being weighed at the barangay health center are difficult to examine because so few children did not receive these services. Thus the impact of the utilization of each ECD treatment is likely to provide a biased estimate of the overall ECD program effect. Nevertheless, we did experiment with defining treatment as whether the child had any contact with the barangay health station in the year prior to the survey for children living in program regions 6 and 7 only. We
} 
In general, $\mathrm{Y}$ is determined not only by the program, if at all, but also by observed characteristics of the child and the child's family and community (X); by a host of factors, also pertaining to the child, the family and the community, that are unobserved (Z); and by a stochastic error term (e). In each period t, the household makes decisions that determine $Y$ given the value of all capital stocks at the end of the previous period (including those for child human capital accumulation) and current and expected future prices, resources and local service options, all of which are included in $\mathrm{X}$ and $\mathrm{Z}$. The capital stocks are assumed to incorporate all the information on past prices, resources, and stochastic shocks. A linear approximation of this relation is:

(1) $Y_{t}=a P_{t}+b X_{t}+c Z_{t}+e_{t}$, where each variable is a vector and coefficients are matrices. ${ }^{14}$ Establishing a counterfactual-or what would have happened if those who were exposed to
treatment had not been exposed to treatment

To obtain a consistent estimate of the parameter $a$ in relation (1), we would like to compare what happened to a given child with the ECD program option to the identical child (in the identical family and the identical community) at the identical time without the ECD program option. Such a comparison, however, is not possible because it is not possible to observe the same child at the same time both with and without the program option. An experimental design permits such a comparison by randomly assigning children to treatment versus non-treatment so that the distributions of child observed and unobserved characteristics with the program option are the same as the distributions of those characteristics for the children without the program option. In the absence of a good experiment, a good estimate of $a$ cannot be obtained simply by comparing the mean values of $\mathrm{Y}$ with and without the program, or by using simple standard estimation methods such as ordinary least squares (OLS) because critical factors in $\mathrm{X}$ and $\mathrm{Z}$ are likely to differ between program and non-program areas.

Table 6 compares some characteristics of municipalities, barangays, and households for those children residing in program regions compared to those not residing in program regions. Municipal leaders in program areas are less likely to have more than a college education than those in non-program areas. The number of available health

take the treatment variable as occurring in the survey round subsequent to the round after which the program began in a barangay. For example, if the program began after Round 1, we take the Round 2 value for whether the child went to the health center. Because the treatment indicator refers to the year before the survey, it is conceivable that its values could have occurred prior to the start of the program. Since we do not know the precise timing of when children visited the health center, we cannot elucidate this issue further. Using Round 3 values of the treatment variable did not change the results appreciably. The results (not shown here, but available from the authors) indicate that among the unmatched and matched samples of children, for all indicators, there is no evidence that there is a statistically significant program impact. The sign and magnitude of the estimates tend to vary erratically across the age and duration cells. However, for the reasons given above describing the nature of the ECD program, we think that these attempts to estimate the effect of the "treatment on the treated" are not very informative.

${ }^{14}$ Each element in each vector could be indexed by its level of aggregation (such as the child, household, or community), but for simplicity of exposition, these corresponding subscripts have been omitted here. 
personnel (per 1000 population) is not significantly different in program areas as compared to non-program areas, with the exception of midwives who are more numerous in program areas. Barangay leaders in program areas are more likely to be born in the same barangay and have about a half year more of schooling than leaders in non-program areas. Day care centers are significantly fewer in program barangays compared to non-program barangays. Socioeconomic characteristics averaged at the barangay or household level do not differ markedly between program and non-program areas, except that children in program areas live in households that are better-off with respect to availability of electricity, presence of markets in the barangay, and parents' schooling.

Table 6 thus indicates that the samples of children, who live in program and nonprogram areas, respectively, are not balanced with respect to some covariates that may be important determinants of ECD or of participation in the ECD program. In the absence of a randomized allocation of children to the program, our preferred approach for establishing a counterfactual group is a difference-in-difference propensity score matching method that allows obtaining control samples that are as similar as possible to those in the program areas in terms of observed characteristics while controlling for all fixed unobserved characteristics.

The difference-in-difference method controls for all unobserved fixed child (e.g., innate health), family (e.g., relevant aspects of home environment that affect ECD) and community (e.g., relevant aspects of the community that may directly affect ECD and the placement of ECD-related programs ${ }^{15}$ ) variables and all community variables that exhibit secular changes that are common across program and non-program areas. Because we have baseline data as well as subsequent data for both program (superscript "P”) and nonprogram (superscript “NP”) areas, relation (1) can be restated as relation (2):

(2) $\Delta \mathrm{Y}^{\mathrm{P}}-\Delta \mathrm{Y}^{\mathrm{NP}}=a\left(\Delta \mathrm{P}^{\mathrm{P}}-\Delta \mathrm{P}^{\mathrm{NP}}\right)+b\left(\Delta \mathrm{X}^{\mathrm{P}}-\Delta \mathrm{X}^{\mathrm{NP}}\right)+c\left(\Delta \mathrm{Z}^{\mathrm{P}}-\Delta \mathrm{Z}^{\mathrm{NP}}\right)+\left(\Delta \mathrm{e}^{\mathrm{P}}-\Delta \mathrm{e}^{\mathrm{NP}}\right)$.

For all fixed unobserved variables $\Delta \mathrm{Z}^{\mathrm{P}}=\Delta \mathrm{Z}^{\mathrm{NP}}=0$, so they do not bias the estimates of the parameter $a$. For time-varying unobserved variables that are common across observations, such as macroeconomic trends, $\left(\Delta \mathrm{Z}^{\mathrm{P}}-\Delta \mathrm{Z}^{\mathrm{NP}}\right)=0$, again not causing bias in the estimate of $a$ in relation (2). The propensity score matching method utilizes information on the observed baseline characteristics $\mathrm{X}$ of children, their families, and their communities to identify and match treatment and control sample children on the elements of X. For our propensity score matching estimates, we estimate whether children have an offer of

\footnotetext{
${ }^{15}$ Program placement and program characteristics can be determined simultaneously such that the effective error in relation (1) (i.e., $c Z_{t}+e_{t}$ ) includes components that determine the presence of a program in the community, P, as well as determine Y. For example, if the Philippine government favored poorer areas in its selection of the program areas as it stated it would, such areas are likely to be poorer in a number of unobserved dimensions that affect child development.
} 
treatment as dependent on the set of $\mathrm{X}$ variables listed in Appendix C. ${ }^{16}$

Table 6. Characteristics of Program and Non-Program Samples at Baseline, Philippines ECD Study

\begin{tabular}{|c|c|c|}
\hline Level of Aggregation & Program & Non-program \\
\hline \multicolumn{3}{|l|}{ Municipality } \\
\hline Municipality in poorest income class & 63.0 & 69.6 \\
\hline \multicolumn{3}{|l|}{ Municipal Mayor: } \\
\hline Has completed college+ level of schooling & 17.5 & $40.2 *$ \\
\hline Born in sample municipality & 77.1 & 51.8 \\
\hline Belongs to civic or political group & 95.1 & 97.3 \\
\hline \multicolumn{3}{|l|}{ ECD and Health Services per 1000 population } \\
\hline Doctor & .032 & .033 \\
\hline Nurse & .078 & .077 \\
\hline Midwife & .271 & $.226^{*}$ \\
\hline Barangay Health workers & 3.24 & 3.75 \\
\hline \multicolumn{3}{|l|}{ Barangay } \\
\hline \multicolumn{3}{|l|}{ Barangay Captain } \\
\hline Years of schooling & 11.8 & 11.3 \\
\hline Born in sample barangay & 68.1 & 56.2 \\
\hline Belongs to civic or political group & 80.1 & 81.8 \\
\hline \multicolumn{3}{|l|}{ ECD and Health Services per 1000 population } \\
\hline Health Centers & .39 & .629 \\
\hline Public Hospitals & .022 & .117 \\
\hline Private Hospitals & .021 & .117 \\
\hline Day Care Centers & .699 & $1.3^{*}$ \\
\hline Public Elementary Schools & .447 & .722 \\
\hline \multicolumn{3}{|l|}{ Other infrastructure in barangay: } \\
\hline Market & 32.9 & $8.0^{*}$ \\
\hline Piped water connection & 32.7 & 33.7 \\
\hline Paved Roads & 36.1 & 39.2 \\
\hline \multicolumn{3}{|l|}{ Household } \\
\hline Piped water & 27.6 & 32.5 \\
\hline Flush/water seal toilet & 58.2 & 57.3 \\
\hline Mean Income (SE) & $69,174(5,502)$ & $59,792(4,646)$ \\
\hline Number of rooms & 2.66 & 2.67 \\
\hline Electricity available & 57.0 & $45.8^{*}$ \\
\hline Minutes to nearest road & 7.2 & 9.6 \\
\hline
\end{tabular}

\footnotetext{
${ }^{16}$ The non-program area, particularly Region 8, would be a less desirable control group, conditional on matching children on X, if there were important ongoing ECD-related activities (e.g., related to external donors or non-governmental organizations) distinct from the government's ECD package of services. However, only four of the 96 barangays in the non-program region report that there are other such funding agencies providing assistance to them (OPS 2005). This affirms the comparison between the ECD program and the non-program areas as being one between areas that have received the program inputs and those that have not received these inputs or any other significant ECD-related interventions.
} 
*Mean is significantly different between program and non-program samples at the .05 level.

\section{Varying implementation lags}

Discussions with the ECD project management office and field administrative data indicated that there was substantial variance in the timing of the implementation of the project across municipalities and barangays, where implementation means procurement and receipt of material inputs and provider training related to the program. This variance implies differences in the duration of exposure to the program across program areas, and thus differences in the amount of time that the interventions could have had an impact. If program effects are estimated as if the program began before its actual effectiveness at the barangay level, then those effects might be underestimated. Many evaluations do not take into account this variation in the duration of program implementation, often because the program start is presumed to be well-defined (though in reality official starting dates often do not reflect start-up delays on the ground) and also because data on timing are not available. One exception is the analysis of the Bolivian PIDI pre-school program mentioned above (Behrman, Cheng and Todd 2004), which explicitly takes into account the dates of enrollment of individual children into the program and find that impact is most clearly observed among children who have been exposed to the program for more than a year, compared with those exposed for less time. Another is the evaluation of PROGRESA by Gertler (2004) who found no program impact after only six months of program exposure, but with 24 months of program exposure the illness rate of the treatment group was 39.5 percent lower than the control group, a difference that is significant at the 1-percent level.

With the help of the central project implementation office, we are able to use administrative data to add another measure of the availability of the program. The mean length of exposure is about 14 months (with a substantial standard deviation of six months). (Appendix Figure B.1 shows the distribution of the length of exposure to the program.) Table 7 shows the distribution of children, by age in years at Round 3, across four exposure categories. We restrict our estimates to children who lived in barangays that had at least four months of exposure at Round 3 because children with less than four months of exposure are unlikely to have had enough exposure to the program to show any measurable impact, particularly given initial start-up problems in modifying effectively existing programs or in introducing new ones. As shown in Table 7, this involves dropping 252 children from the analysis. Two barangays received the program inputs about a year and a half before Round 1 , so we exclude these two barangays ( $\mathrm{N}=33$ children); in these cases the matching variables, measured at baseline, are not likely to be exogenous to the 
program initiation. Virtually all barangays had received the program by Round 3, with one exception $(\mathrm{N}=32)$ which we also excluded from the analysis.

Based on information on the start of the program provided by the project implementation office that controls procurement and the release of funds, the duration of exposure apparently was dependent on administrative lags in central procurement rules and centralized actions rather than on preferences in the program areas. Data from this office indicate that due to lags in disbursements, in 70 percent of program barangays, the program did not get started until after the first round of data was collected, and in another 29 percent, not until after the second round. In the second round, lack of funds or delays in releasing funds were a problem reported by 28 of the 33 municipality-level ECD project teams with available data, and was the most common implementation problem they named (OPS 2005).

Table 7. Percentage Distribution of Children across Exposure Categories by Age, Philippines ECD Study

\begin{tabular}{lcrrrr}
\hline \hline $\begin{array}{l}\text { Age in years } \\
\text { (Round 3) }\end{array}$ & $<$ months & 4-12 months & 13-16 months & 17+ months & Total \\
\hline 2 & $4.42(24)$ & $33.2(180)$ & $32.6(177)$ & $29.8(162)$ & $100(543)$ \\
3 & $6.13(53)$ & $33.7(291)$ & $28.4(245)$ & $31.8(275)$ & $100(864)$ \\
4 & $6.51(50)$ & $34.4(264)$ & $28.4(218)$ & $30.7(236)$ & $100(768)$ \\
5 & $5.67(49)$ & $39.2(339)$ & $24.1(209)$ & $31.1(269)$ & $100(866)$ \\
$6+$ & $6.92(76)$ & $36.7(404)$ & $28.0(308)$ & $28.3(311)$ & $100(1,099)$ \\
Total N & 252 & 1,478 & 1,157 & 1,253 & 4,140 \\
\hline
\end{tabular}

Notes: Numbers of children are in parentheses.

Our estimates of impact are based on nearest-neighbor propensity score matching of a set of treatment and control observations using the variables described in Appendix C. Using the "nnmatch.ado" routine in STATA 9 (see Abadie, et al. 2004), we calculate the sample average treatment effect (or the difference-in-difference estimator in our case). We condition our estimates on the joint distribution of children's age (at Round 3) and a discrete measure of their duration of program exposure-distinguishing according to 4-12 months, 13-16 months, and 17+ months duration ${ }^{17}$ —and we specify robust standard errors. This strategy allows us to uncover potentially valuable information about how children of different age groups respond to varying program exposure. Table 7 shows that there is a sufficient number of children in program areas in all the age/duration combinations to estimate impacts within each class.

\section{4. $\quad$ Results}


Table 8 summarizes our difference-in-difference propensity score matching “intentto-treat" program impact estimates by dividing into three groups the 15 child development indicators that we consider. ${ }^{18}$ Additional estimates are provided in Appendix D. The three groups are:

I. Predominately positive program impacts (nine indicators)

II. Mixed or virtually no program impacts (four indicators)

III. Predominately negative program impacts (two indicators)

For each indicator, we estimate the impact for each of 15 age-duration groups (i.e., five ages at Round 3, three durations). Column 1 in Table 8 gives the number of these estimates that are significantly positive (in the sense of improving child development, so a reduction in wasting, stunting, diarrhea, worms and anemia is counted as a positive impact) at the standard 0.05 level. Column 2 gives the number of estimates that are significantly negative, and column 3 gives the percentage of the significant estimates that are positive. The 15 indicators that we considered are ordered from highest to lowest in terms of percentage of significant coefficient estimates that indicate positive program impact (column 3). Column 4 gives the mean impact in terms of sample standard deviations for the indicators for the significantly positive impacts. Column 5 , similarly, gives the mean impact in terms of standard deviations for the indicators for the significantly negative impacts.

Group I, predominantly positive program impacts, includes 9 of the 15 indicators (or 60 percent) that we consider - all seven domains for cognitive, social, motor and language development plus weight-for-height $\mathrm{Z}$ scores and the proportion wasted. For Group I, 85 percent of the significant coefficients estimates indicate positive program impact (see last row of table), with 100 percent for five of the nine indicators. The magnitudes of the estimated significant positive impacts generally are fairly large, averaging 0.62 of a standard deviation across the nine indicators. But the variation across indicators also is considerable; the largest impacts are for the two language indicators and the smallest are for weight-for-height, particularly the proportion wasted.

Group II, mixed or no program impacts, includes 27 percent of the indicators: the proportions with diarrhea, with worms and stunted and the height-for-age $\mathrm{Z}$ score. We note that for two indicators in Group II, diarrhea and worms, there are positive program impacts

\footnotetext{
${ }^{17}$ Since the age at Round 3 is given, the exposure that is reported is the exposure for the indicated number of months before the Round 3 age.

${ }^{18}$ The division between Groups I and II is somewhat arbitrary, with the proportion wasted (66.7 percent) in Group I and the proportion with diarrhea (60 percent) in Group II. But there are twice as many significantly positive coefficient estimates for the former as for the latter, and if a significance level of 0.10 is used, the percentage for the proportion wasted increases (to 70 percent) but is not changed for the proportion with diarrhea. Therefore we distinguish between these two indicators in our assignment to the three groups.
} 
for the younger children even though the overall impacts when the older ages are included are mixed. The more detailed presentation of the estimates for Group II in Table D.2 indicates that among two year olds, the proportions with diarrhea are significantly reduced for all three durations and for two and three year olds the proportions with worms are significantly reduced for those with $17+$ months of duration.

Table 8. Summary of Estimated Intent-to Treat Positive and Negative Program Impacts for Nearest Neighbor Matched Estimates with Control for Attrition, Philippines ECD Study

Mean Magnitude of

Number of Significant Coefficients Significant Effects (in terms with Program Effect of sample SDs)

Positive Negative \% Positive Positive Negative

Group I: Predominately positive program impacts

Cognitive skills $\quad 9 \quad 0$

Expressive language

Gross motor skills

Self-help

Fine motor skills

Social-emotional skills

Weight-for-height z Score

Receptive language

Proportion wasted

$\begin{array}{ll}9 & 0 \\ 7 & 0 \\ 7 & 0\end{array}$

$7 \quad 0$

$7 \quad 0$

$5 \quad 0$

$10 \quad 1$

$\begin{array}{ll}7 & 1\end{array}$

$6 \quad 2$

63
Group II: Mixed or virtually no program impacts

Proportion with diarrhea

Proportion with worms

Proportion stunted

Height-for-age z Score
32

$2 \quad 2$

$3 \quad 5$

$0 \quad 1$

Group III: Predominately negative program impacts

Proportion anemic

Hemoglobin count

Totals or averages across groups

All groups

Group I

Notes: "Significant" refers to the 0.05 level.

"na” means "not applicable."

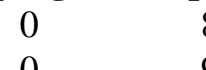

$0 \quad 9$

$\begin{array}{rcc}100.0 & 0.553 & \text { na } \\ 100.0 & 1.085 & \text { na } \\ 100.0 & 0.791 & \text { na } \\ 100.0 & 0.334 & \text { na } \\ 100.0 & 0.647 & \text { na } \\ 90.9 & 0.545 & -0.468 \\ 87.5 & 0.234 & -0.370 \\ 75.0 & 1.43 & -0.475 \\ 66.7 & -0.014 & 0.010 \\ & & \\ 60.0 & -0.035 & 0.016 \\ 50.0 & -0.085 & 0.067 \\ 37.5 & -0.04 & 0.048 \\ 0 & \text { na } & -0.292\end{array}$

$8 \quad 0$

$\begin{array}{lll}0 & \text { na } & 0.089\end{array}$

$0 \quad$ na $\quad-0.539$

Group III, predominantly negative program impact, includes the proportion anemic and hemoglobin count. For these two indicators there are a fairly large number of significant coefficient estimates, and all indicate negative program impact. This is a bothersome result although these two are only 13 percent of the total indicators that we consider, and we do not have a good explanation as to why the program had this effect. Unless anemia were of much greater concern than other aspects of child development reflected by the indicators in Group I (which does not seem to be the case), these negative program effects should not be interpreted to dominate in the overall evaluation of the program. It would be desirable to learn why they occur, however, and to consider whether it is worth the costs of rectifying whatever causes these negative outcomes. 
Table 8 includes only summaries of the effects, without indication of the individual coefficient estimates for each indicator by age and duration of exposure that may be important for a better understanding of program impacts. Table 9 therefore gives the individual estimates for each of the age and duration cells for Group I (see Table D2 for similar estimates for Groups II and III).

Table 9. Intent-to-Treat Impacts by Age in Years (at Round 3) and Duration Class Based on Difference-in-Difference Nearest Neighbor Propensity Score Matching Estimates: Group I Indicators - Predominately Positive Program Impacts

\begin{tabular}{|c|c|c|c|c|}
\hline \multirow[t]{2}{*}{ ECD Indictors } & \multirow{2}{*}{$\begin{array}{c}\text { Age at } \\
\text { Round } 3\end{array}$} & \multicolumn{3}{|c|}{ "Duration of Exposure (months) } \\
\hline & & 4 to 12 & 13 to 16 & $17+$ \\
\hline \multirow[t]{5}{*}{ Cognitive skills } & 2 & $0.917(.122)^{*}$ & $1.24(.128)^{*}$ & $1.07(.094)^{*}$ \\
\hline & 3 & $0.278(.096)^{*}$ & $0.362(.112)^{*}$ & $0.426(.098)^{*}$ \\
\hline & 4 & $0.031(.094)$ & $-0.225(.116)^{\sim}$ & $0.034(.121)$ \\
\hline & 5 & $0.192(.088)+$ & $0.116(.143)$ & $0.043(.097)$ \\
\hline & $6+$ & $0.169(.102) \sim$ & $0.242(.100)+$ & $0.313(.095)^{*}$ \\
\hline \multirow{5}{*}{ Expressive language } & 2 & $1.02(.213)^{*}$ & $1.60(.178)^{*}$ & $1.31(.190)^{*}$ \\
\hline & 3 & $0.635(.146)^{*}$ & $0.517(.126)^{*}$ & $0.918(.131)^{*}$ \\
\hline & 4 & $-0.068(.113)$ & $0.130(.184)$ & $0.358(.113) *$ \\
\hline & 5 & $0.156(.092) \sim$ & $-0.050(.095)$ & $0.156(.089) \sim$ \\
\hline & $6+$ & $-0.251(.132)^{\sim}$ & $0.077(.083)$ & $-0.069(.091)$ \\
\hline \multirow{5}{*}{ Gross motor skills } & 2 & $1.14(.160)^{*}$ & $1.21(.161)^{*}$ & $1.49(.170)^{*}$ \\
\hline & 3 & $0.070(.136)$ & $0.401(.131)^{*}$ & $0.286(.106)^{*}$ \\
\hline & 4 & $-0.019(.100)$ & $-0.069(.108)$ & $0.244(.091)^{*}$ \\
\hline & 5 & $0.069(.109)$ & $0.201(.125)$ & $0.275(.098)^{*}$ \\
\hline & $6+$ & $-0.135(.126)$ & $-0.009(.152)$ & $0.040(.103)$ \\
\hline \multirow[t]{5}{*}{ Self-help } & 2 & $0.284(.113)^{+}$ & $0.241(.118)+$ & $0.630(.142)^{*}$ \\
\hline & 3 & $0.149(.104)$ & $0.250(.119)+$ & $0.325(.108)^{*}$ \\
\hline & 4 & $0.365(.091)^{*}$ & $0.228(.104)+$ & $0.112(.096)$ \\
\hline & 5 & $0.078(.098)$ & $-0.018(.125)$ & $-0.061(.124)$ \\
\hline & $6+$ & $-0.078(.090)$ & $0.070(.088)$ & $-0.123(.082)$ \\
\hline \multirow[t]{5}{*}{ Fine motor skills } & 2 & $0.463(.206)+$ & $0.741(.158)^{*}$ & $0.793(.158)^{*}$ \\
\hline & 3 & $-0.122(.144)$ & $0.144(.135)$ & $0.165(.099) \sim$ \\
\hline & 4 & -0.043 (.119) & $-0.029(.109)$ & $0.103(.127)$ \\
\hline & 5 & $0.332(.104)^{*}$ & $0.177(.166)$ & $0.289(.120)+$ \\
\hline & $6+$ & $0.166(.123)$ & $0.162(.112)$ & $0.020(.123)$ \\
\hline \multirow[t]{5}{*}{ Social-emotional } & 2 & $0.800(.161)^{*}$ & $0.663(.152)^{*}$ & $0.993(.121)^{*}$ \\
\hline & 3 & 0.028 (.123) & $0.425(.096)^{*}$ & $0.535(.101)^{*}$ \\
\hline & 4 & $-0.425(.119)^{*}$ & $0.308(.132)+$ & $0.189(.100) \sim$ \\
\hline & 5 & $0.036(.090)$ & $0.308(.109)^{*}$ & $0.322(.105)^{*}$ \\
\hline & $6+$ & $0.044(.096)$ & $0.220(.099)+$ & $0.374(.096)^{*}$ \\
\hline \multirow[t]{5}{*}{ Weight-for-height Z } & 2 & $0.173(.082)+$ & $-0.327(.081)^{*}$ & $0.142(.138)$ \\
\hline & 3 & $0.140(.095)$ & $0.099(.071)$ & $-0.085(.071)$ \\
\hline & 4 & $0.127(.055)+$ & $0.261(.052)^{*}$ & 0.057 (.045) \\
\hline & 5 & $0.270(.041)^{*}$ & $0.162(.058)^{*}$ & $0.025(.045)$ \\
\hline & $6+$ & $0.209(.055)^{*}$ & $0.245(.041)^{*}$ & $0.085(.044) \sim$ \\
\hline \multirow[t]{3}{*}{ Receptive language } & 2 & $1.00(.236)^{*}$ & $1.65(.200)^{*}$ & $1.78(.183)^{*}$ \\
\hline & 3 & $0.328(.134)+$ & $1.15(.154)^{*}$ & $1.06(.147)^{*}$ \\
\hline & 4 & $-0.153(.133)$ & $0.217(.202)$ & $0.226(.146)$ \\
\hline
\end{tabular}




\begin{tabular}{lclcc}
\hline & 5 & $-0.164(.124)$ & $-0.260(.117)$ & $-0.115(.092)$ \\
Proportion wasted & $6+$ & $-0.248(.111)^{+}$ & $-0.524(.139)^{*}$ & $0.0002(.109)$ \\
& 2 & $-.107(.029)^{*}$ & $.068(.021)^{*}$ & $-.013(.033)$ \\
& 3 & $-.112(.029)^{*}$ & $-.064(.033)+$ & $-.069(.028)^{+}$ \\
& 4 & $-.028(.017)$ & $.001(.018)$ & $-.052(.019)^{*}$ \\
& 5 & $-.043(.019)+$ & $.026(.013)+$ & $.034(.013)+$ \\
& $6+$ & $-.0007(.012)$ & $-.024(.013) \sim$ & $-.004(.005)$ \\
\hline
\end{tabular}

Note: Standard errors in parentheses. $\sim \mathrm{p}<.10+\mathrm{p}<.05 * \mathrm{p}<.01$.

Table 10. Distribution of Significant Positive Effects by Age and Months of Exposure to Treatment for Group I (Predominately Positive Impacts)

\begin{tabular}{lccccc} 
& \multicolumn{3}{c}{ Months of Exposure } & Total & $\begin{array}{c}\text { Mean Impact } \\
\text { (Sample SDs) }\end{array}$ \\
\cline { 2 - 4 } Age in Years (Round 3) & $4-12 \mathrm{~m}$ & $13-16 \mathrm{~m}$ & $17+\mathrm{m}$ & & \\
\cline { 1 - 4 } 2 & 9 & 7 & 7 & 23 & 0.90 \\
3 & 4 & 7 & 7 & 18 & 0.49 \\
4 & 2 & 3 & 3 & 8 & 0.26 \\
5 & 4 & 2 & 3 & 9 & 0.24 \\
$6^{+}$ & 1 & 3 & 2 & 6 & 0.29 \\
Total by duration & 20 & 22 & 22 & 64 & \\
Mean impact by duration & 0.60 & 0.70 & 0.72 & & \\
\hline
\end{tabular}

Among children below age four at the time of Round 3, there has been a substantial improvement in cognitive, social, motor and language development in all seven domains for those in program areas relative to non-program areas. Table 9 indicates that for twoyear-olds, gross motor skills are about 1.1 to 1.5 of a standard deviation higher in program areas than in non-program areas. For two- and three-year olds exposed to the program for at least 17 months, expressive and receptive language skills are about .92 to 1.8 standard deviations higher. Program impacts on cognitive skills at young ages range from .92 to 1.2 standard deviations (for two year olds) and .28 to .43 standard deviations (for three year olds). The weight-for-height Z-score among older children (those four and older) are significantly higher among program compared to non-program children by about .16 to .27 of one standard deviation (though similar positive impacts are not evident among children who have been exposed to the program for $17+$ months).

Table 10 summarizes the significant and positive (at the .05 level) impact estimates for Group I across all the indicators. It gives the number of significant and positive estimates for each of the 15 age-duration groups, as well as the marginal totals for the three duration and the five age groups. In addition, the last column gives the mean estimated impact in terms of sample deviations by age and the last row gives the mean estimated impact in terms of sample deviations by the three duration categories. Though for some of the indicators the estimates in Table 9 indicate significant positive responses primarily after fairly long duration of program exposure (e.g., after 17 months for gross motor skills, after 13 months for social-emotional skills), the last two rows of Table 10 suggest only 
slight evidence of increased impact with greater duration. In particular, there is a 10 percent increase in the prevalence of positive coefficients between exposure of 4-12 months to $13+$ months and an increase from 0.60 to 0.70 standard deviations of the outcomes with the same increase in exposure. On the other hand, the summary in the last two columns of Table 10 indicates substantial concentration of significant positive program impacts among younger children: 64 percent (or 41 of 64) of these impacts are for children two- or three-years old at the time of Round 3. The average magnitude of the impacts is 0.90 standard deviations for two-year olds and 0.49 standard deviations for three-year old, but only in the 0.24-0.29 range for children older than three.

\section{Conclusion}

We analyze the effects of an important ECD initiative in a developing country setting. The individual parts of the package of services delivered by the program in the Philippines are generally not new, but the program has changed the country's approach to ECD by linking sectoral policies that affect young children and by integrating interventions that include center-based and home-based programs. We use rich and detailed longitudinal information on children, their families and communities, as well as data on the program itself, to estimate treatment effects. The difference-in-difference propensity score matching methods we use allow impacts to vary by both exposure to the program and the ages of children while controlling for observed characteristics and unobserved characteristics that are fixed and display common trends between program and non-program areas. Our results provide important insights on the effectiveness of ECD interventions in this low income setting.

The findings suggest that the ECD program is benefiting children in important respects. We find significant positive intent-to-treat impacts on the majority of the indicators of child development that we consider, particularly those related to child cognitive, social, motor skills and language development as well as short-term nutritional status. The incorporation of information about the variation of program exposure and child age is valuable because we can test to what extent the program impacts are sensitive to duration of exposure or are concentrated among particular age ranges of children. We find that the program impacts seem to increase with duration, particularly with duration beyond 12 months. We also find that positive program effects vary depending on the child's age. In particular, cognitive, social, motor and language development among children below age four at the time of the final survey round improved significantly and substantially in program areas relative to non-program areas. Younger children exhibit faster rates of change in psycho-social development than do older children, and thus may be more receptive to interventions that aim to improve developmental outcomes. These impacts are not trivial: among two- and three-year-olds exposed to the program, Z-scores are one-half to 1.8 of a standard deviation higher for motor and language development. The prevalence and magnitudes of estimated positive program impacts are much less for older children. 
There are several components of the program that are likely to have produced the positive impacts on cognitive, social, motor and language development, weight-for-height Z-scores, and wasting. At the municipality level, the program can be credited with spreading infant feeding programs, parent education workshops, and home-based day care. The program also has funded the construction of additional day-care centers, upgrading of existing health facilities, and increases in the supplies available to these centers. In program areas compared to non-program areas, we document significantly higher involvement and training of service providers in providing a range of services including primary health care, teaching parents about childrearing, monitoring new cases, growth monitoring, following up with families via home visits, case referral, and providing food and micronutrient supplements to children. The program further has installed new service providers who are heavily involved in parent education via home visits as well as other services such as growth monitoring and feeding programs. More in-depth analysis of our data on these service providers and the facilities in which they work is planned for the future in the hope of better identifying the factors that might explain the gains in child health and cognitive, language, motor development and short-term nutrition in the ECD program areas. 


\section{Appendix A. Components of ECD Program in the Philippines}

\section{Expanded Program on Immunization}

Integrated Management of Childhood Illnesses (IMCI) Program

Integrated Maternal and Child Health (IMCH) Program

\section{Protein Energy \\ Malnutrition (PEM) \\ Program \\ Growth Monitoring \\ Program \\ Infant Feeding Program}

\section{Micronutrient \\ Malnutrition Prevention and Control Program}

\section{Vitamin A \\ Supplementation \\ Program \\ Iron Supplementation \\ Program \\ Iodine Supplementation \\ Program \\ Early Child Education \\ Program}

Provides immunization services to infants and young children to protect them from immunizable diseases (tuberculosis, diphtheria, pertussis, tetanus, hepatitis B, measles and polio); includes also immunization of pregnant mothers with tetanus toxoid to prevent tetanus neonatorum.

In the ECD project, this refers to the provision of additional inputs to the EPI Program in all provinces of the program regions including replacement of cold chain equipment (as necessary), training of cold chain technicians in cold chain management, maintenance and repair, training of primary health care staff in EPI skills and reproduction of EPI information, education communication materials and monitoring charts.

A range of services focused on the accurate diagnosis, management and treatment of illnesses among children in outpatient settings, in order to improve management of childhood illnesses (like respiratory infections, pneumonia, diarrhea) with aspects of nutrition, immunization and other factors influencing child health including maternal health.

In the ECD project, this refers to the improvement in diagnosis, management and treatment of common childhood diseases and malnutrition with the training for health providers, supply of delivery and diet kits to improve case management conditions affecting the newborn.

A range of services to protect the health of mothers and children from endemic diseases, nutritional disorders, risks and illnesses brought about by pregnancy and childbirth. This program caters to mothers, infants and young children (0-4 years old). In relation to child health, the IMCH program is concerned with prenatal, natal and postnatal services, under five clinic and promotion of breastfeeding.

Services to address the protein energy malnutrition problem with the provision of growth monitoring and infant feeding programs among others.

Monitors the growth of children under six years old.

Provides food supplements to children who are diagnosed as malnourished.

Provides services that address protein energy malnutrition (PEM), and micronutrient deficiencies.

At the ECD level, this refers to the prevention, management and control of major micronutrient deficiencies (iron, iodine and vitamin A) in preschoolers through mix of direct supplementation, food fortification and deworming of children, provision of weighing scales for infants to identify low birth weight babies requiring iron supplements, deworming tablets and social marketing to promote comprehensive food fortification.

A range of services to address the vitamin A deficiency of children and mothers; includes provision of free vitamin A capsules.

A range of services to address the iron deficiency, particularly of children and mothers; includes the provision of free iron syrup, tablets/capsules.

A range of services to address the iodine deficiency; includes provision of free iodized capsules and iodized salt.

Administers an eight-week enriched early child experience (ECE) curriculum that helps children bridge the gap between home and school and improves their readiness for formal education. 


\section{Day Care Program}

Parent Effectiveness Services Program

Day Care Mom Program
In the ECD project, this refers to the improvement of the child readiness through an eight-week curriculum module in Grade 1 that incorporates innovative and participatory approaches and complementary health and nutrition inputs (iron supplementation and deworming) to first graders. This program includes the review and improvement of the ECE curriculum, support for training of teachers in the new Grade 1 curriculum, the reproduction and distribution of teaching materials, training of trainers and teachers and the distribution of iron supplements and deworming tablets for Grade 1 entrants. Managed by the Department of Education.

A range of services to provide early education to children age 3-5 years, including the provision of day care centers.

A range of services to enhance parental involvement in child care and development and teach parents more efficient ways of childrearing and what the children need for their physical and mental development. The Child Development Worker conducts workshops on these services.

In the ECD project, this refers to the upgrading of the PES program with the provision of the mother and child book (that records the child growth from birth to age six) and distributing the parents' ECD manual. In the context of the LGU, the PES includes the training of the child development worker as the key PES provider and responsible for community-based parent education. Managed by the DSWD in coordination with the Department of Education (incorporated into the Teacher Child Parent Program) and the $\mathrm{DOH}$ (incorporated into the health education programs).

A range of services and support provided by day care moms to provide childminding services to children under three years old. 


\section{Appendix B. Additional Tables and Analyses on Attrition}

Table B.1. Attrition by Treatment Status, ECD Study

\begin{tabular}{lrrr}
\hline & & Non- & \\
Follow-up Status & Program & program & Total \\
\hline Total Interviewed in Round 1 (baseline) & 4786 & 3136 & 7922 \\
Stayed in Round 1 sample barangay in all three rounds & 4197 & 2577 & 6774 \\
Total Lost to Follow-up & 589 & 559 & 1148 \\
Reasons for Attrition: & & & \\
Outmigrated and not followed-up & 276 & 276 & 552 \\
Outmigrated but tracked in new barangay & 206 & 193 & 399 \\
Refusal & 52 & 36 & 88 \\
Non-availability & 28 & 40 & 68 \\
Deaths & 17 & 11 & 28 \\
No information & 10 & 3 & 13 \\
\hline
\end{tabular}

Note: Cell counts refer to number of children.

Table B.2. Association between Attrition and Baseline Characteristics, ECD Study ${ }^{\mathrm{a}}$

\begin{tabular}{|c|c|c|c|}
\hline & Treatment & Main Effects & $\begin{array}{c}\text { Interactions with } \\
\text { Treatment }\end{array}$ \\
\hline \multicolumn{4}{|c|}{ In Treatment Area } \\
\hline & $\begin{array}{c}-0.244^{*} \\
{[.035]}\end{array}$ & -- & $\begin{array}{c}-0.413^{*} \\
{[.176]}\end{array}$ \\
\hline \multicolumn{4}{|c|}{ Child's Age (years) } \\
\hline 1 & & $\begin{array}{c}0.021 \\
{[.084]}\end{array}$ & $\begin{array}{c}-0.130 \sim \\
{[.073]}\end{array}$ \\
\hline 2 & & $\begin{array}{l}-0.031 \\
{[.086]}\end{array}$ & $\begin{array}{l}-0.123 \\
{[.076]}\end{array}$ \\
\hline 3 & & $\begin{array}{c}0.05 \\
{[.085]}\end{array}$ & $\begin{array}{c}-0.234^{*} \\
{[.077]}\end{array}$ \\
\hline 4 & & $\begin{array}{c}-0.188+ \\
{[.090]}\end{array}$ & $\begin{array}{c}-0.11 \\
{[.077]}\end{array}$ \\
\hline \multicolumn{4}{|c|}{ Parent Characteristics } \\
\hline \multicolumn{4}{|c|}{ Father's Schooling } \\
\hline 7 to 11 years & & $\begin{array}{l}-0.115 \\
{[.073]}\end{array}$ & $\begin{array}{c}0.034 \\
{[.063]}\end{array}$ \\
\hline $12+$ years & & $\begin{array}{c}0.225+ \\
{[.111]}\end{array}$ & $\begin{array}{l}0.276^{*} \\
{[.083]}\end{array}$ \\
\hline \multicolumn{4}{|c|}{ Mother's Schooling } \\
\hline 7 to 11 & & $\begin{array}{l}0.092 \\
{[.068]}\end{array}$ & $\begin{array}{l}-0.032 \\
{[.062]}\end{array}$ \\
\hline $12+$ years & & $\begin{array}{l}-0.061 \\
{[.107]}\end{array}$ & $\begin{array}{l}-0.186 \\
{[.116]}\end{array}$ \\
\hline
\end{tabular}


Father's Age

25-35

0.094

$0.217+$

[.113]

$35+$

$-0.152$

0.075

[.124]

[.119]

Mother's Age

25-35

$-0.221+$

$-0.268 *$

[.075]

[.071]

$35+$

$-0.54+$

$-0.528 *$

[.097]

[.092]

Father absent

0.259

$0.596 *$

[.144]

[.133]

Mother absent

$-0.023$

$-0.031$

[.126]

[.117]

Household Characteristics

Number of rooms

0.023

$-0.013$

Electricity

[.022]

[.019]

$-0.161+$

$-0.059$

[.070]

[.058]

Flush/water seal toilet

$-0.144+$

$0.137+$

[.065]

[.058]

Dirt floors

$-0.148 \sim$

$-0.098$

[.078]

[.084]

Live in community with cement road

$0.201^{*}$

0.029

[.064]

$[.054]$

R square

0.007

0.06

Chi-square (treatment interactions)

36.1

$(\mathrm{p}=.002)$

${ }^{\mathrm{a}}$ Standard errors in brackets. Coefficients are from a probit regression. Attrition refers to all children who did not remain in the sample barangay in all three survey rounds. The omitted categories are child less than 12 months old, 0-6 years of schooling and being less than 25 years old for father and mother respectively. The second and third columns show results from a single regression that includes interactions between treatment status and all covariates. Children in barangays that received the program before the baseline round, for less than four months or after the latest round are excluded. $\sim \mathrm{p}<.10+\mathrm{p}<.05 * \mathrm{p}<.01 . \mathrm{N}=7682$. 
Figure B.1. Distribution of Length of Exposure to ECD Program (Months at Round 3)

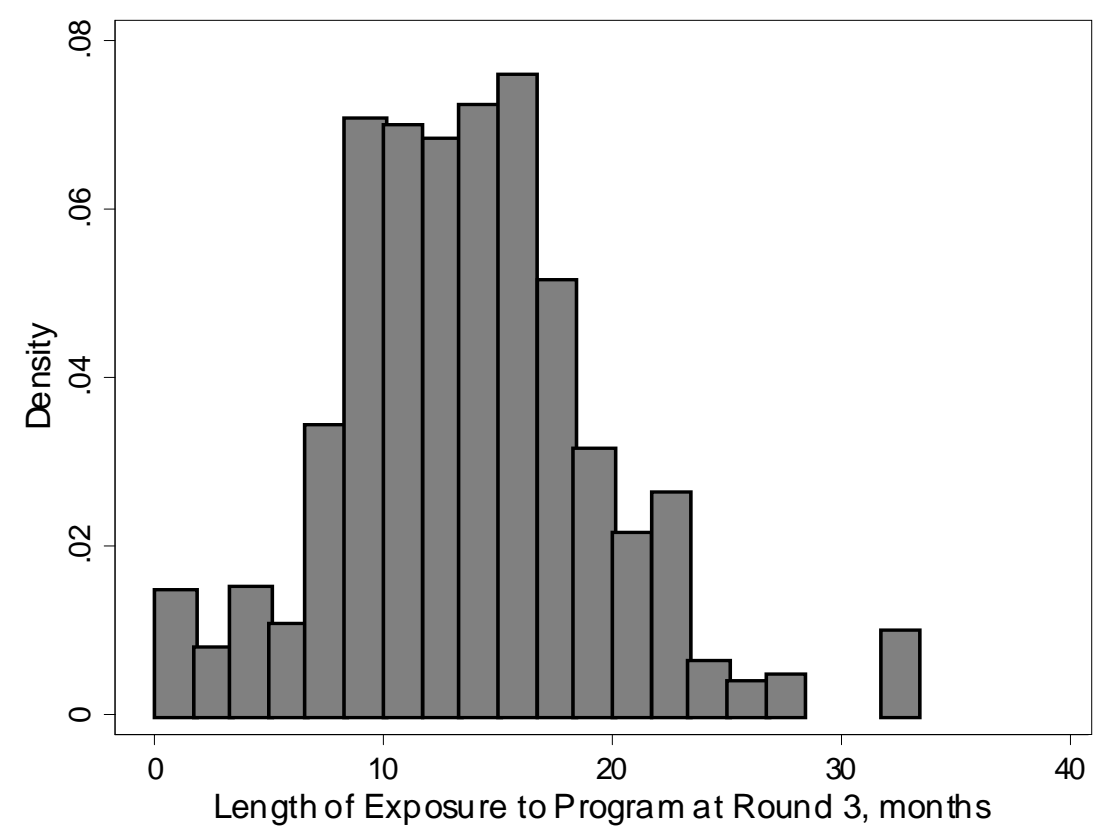

Mean: 13.7

Standard Deviation: 5.8

\section{Appendix C. List of Variables Used in Nearest Neighbor Propensity Score Matching Estimates}

The following variables were used for the intent to treat propensity score matching estimates. All variables are measured at baseline:

Child: had worms in six months prior to survey, stunted, 0,1 or $2+$ siblings, below average cognitive, social, and motor development, sex.

Household: mother's schooling, father's schooling, mother's age, father's age, number of persons in household, mother employed, flush or water sealed toilet present, number of rooms, electricity present, piped water connection from local water district, own television, own home in which household members currently are living, own any motor vehicle, own living room furniture, own a bed, own a fan, nearest road less than five minutes away, distance to health center, household income (quartiles).

Barangay: Captain's schooling, captain born in barangay, captain at least 50 years old, health center in barangay, number of daycare centers in barangay, number of public elementary schools, number of public secondary schools, barangay has cement road, plaza/park and piped water.

Municipality: Number of doctors per 1000 population, number of health centers per 1000 population, number of barangay health workers per 1000 population, municipality in lowest income class, proportion of households with electricity, proportion of households with piped water, citizens can set up meetings with mayor/municipality officials to voice concerns, mayor has more than college education, mayor is at least 50 years old, mayor belongs to civic or political group, population. 


\section{Appendix D. Additional Estimates}

Table D1A. Difference-in-Difference Intent to Treat Impacts for Domains of Cognitive, Social, Motor and Language Development by Age in Years (at Round 3) and Duration Class (without matching), Philippines ECD Study

\begin{tabular}{|c|c|c|c|}
\hline \multirow{2}{*}{$\begin{array}{l}\text { Age/ECD Indicator } \\
\text { Gross Motor }\end{array}$} & \multicolumn{3}{|c|}{ Duration of Exposure (months) } \\
\hline & 4 to 12 & 13 to 16 & $17+$ \\
\hline 2 & $1.08(.284)^{*}$ & $1.44(.224)^{*}$ & $1.41(.247)^{*}$ \\
\hline 3 & $.050(.206)$ & $.420(.189)+$ & $.482(.168)^{*}$ \\
\hline 4 & $-.005(.172)$ & $.111(.206)$ & $.243(.145) \sim$ \\
\hline 5 & $.061(.168)$ & $.467(.185)^{+}$ & $.405(.165)^{+}$ \\
\hline $6+$ & $-.122(.124)$ & $-.019(.132)$ & $-.056(.120)$ \\
\hline \multicolumn{4}{|l|}{ Fine Motor } \\
\hline 2 & $.248(.303)$ & $.421(.249)^{\sim}$ & $.500(.262) \sim$ \\
\hline 3 & $-.057(.254)$ & $.158(.246)$ & $.259(.188)$ \\
\hline 4 & $.040(.207)$ & $.090(.212)$ & $-.156(.193)$ \\
\hline 5 & $.429(.179)+$ & $.472(.235)+$ & $.323(.176)^{\sim}$ \\
\hline $6+$ & $.115(.155)$ & $.162(.182)$ & $.090(.170)$ \\
\hline \multicolumn{4}{|l|}{ Expressive Language } \\
\hline 2 & $1.11(.289)^{*}$ & $1.36(.273)^{*}$ & $1.00(.282)^{*}$ \\
\hline 3 & $.613(.215)^{*}$ & $.674(.239)^{*}$ & $1.01(.172)^{*}$ \\
\hline 4 & $-.111(.162)$ & $-.046(.193)$ & $.086(.157)$ \\
\hline 5 & $.139(.159)$ & $.134(.167)$ & $.140(.152)$ \\
\hline $6+$ & $.069(.119)$ & $.082(.110)$ & $-.143(.102)$ \\
\hline \multicolumn{4}{|l|}{ Receptive Language } \\
\hline 2 & $1.25(.313)^{*}$ & $1.52(.284)^{*}$ & $1.45(.266)^{*}$ \\
\hline 3 & $1.00(.271)^{*}$ & $1.20(.278)^{*}$ & $1.17(.261)^{*}$ \\
\hline 4 & $.064(.175)$ & $.149(.245)$ & $.122(.176)$ \\
\hline 5 & $.074(.188)$ & $.170(.199)$ & $.083(.184)$ \\
\hline $6+$ & $-.109(.154)$ & $-.326(.180) \sim$ & $-.279(.176)$ \\
\hline \multicolumn{4}{|l|}{ Cognitive } \\
\hline 2 & $.911(.200)^{*}$ & $1.12(.182)^{*}$ & $.931(.185)^{*}$ \\
\hline 3 & $.254(.183)$ & $.675(.197)^{*}$ & $.552(.166)^{*}$ \\
\hline 4 & $.083(.165)$ & $-.169(.181)$ & $-.169(.157)$ \\
\hline 5 & $.458(.165)^{*}$ & $.147(.201)$ & $.265(.154) \sim$ \\
\hline $6+$ & $.349(.150)+$ & $.375(.154)^{+}$ & $.417(.132)^{*}$ \\
\hline \multicolumn{4}{|l|}{ Self Help } \\
\hline 2 & $.150(.203)$ & $.363(.178)+$ & $.323(.187)^{\sim}$ \\
\hline 3 & $.136(.167)$ & $.120(.167)$ & $.223(.154)$ \\
\hline 4 & $.353(.163)+$ & $-.087(.162)$ & $-.041(.159)$ \\
\hline 5 & $.047(.183)$ & $.095(.208)$ & $-.208(.180)$ \\
\hline $6+$ & $-.282(.151)$ & $-.130(.156)$ & $-.172(.140)$ \\
\hline \multicolumn{4}{|l|}{ Social-Emotional } \\
\hline 2 & $.468(.268) \sim$ & $.702(.220)^{*}$ & $.691(.223)^{*}$ \\
\hline 3 & $.054(.200)$ & $.526(.206)+$ & $.522(.166)^{*}$ \\
\hline 4 & $-.357(.151)+$ & $.109(.174)$ & $.176(.127)$ \\
\hline 5 & $.099(.175)$ & $.559(.192)^{*}$ & $.365(.171)^{+}$ \\
\hline $6+$ & $-.033(.162)$ & $.144(.167)$ & $.249(.161)$ \\
\hline
\end{tabular}


Table D1B. Difference-in-Difference Intent to Treat Impacts for Anthropometrics, Worms and Diarrhea by Age in Years (at Round 3) and Duration Class (without matching),

Philippines ECD Study

\begin{tabular}{|c|c|c|c|}
\hline \multirow{2}{*}{$\begin{array}{l}\text { Age/ECD Indicator } \\
\text { Height for age Z scores }\end{array}$} & \multicolumn{3}{|c|}{ Duration of Exposure (months) } \\
\hline & 4 to 12 & 13 to 16 & $17+$ \\
\hline 2 & $.022(.208)$ & $-.115(.197)$ & $-.180(.201)$ \\
\hline 3 & $-.069(.172)$ & $-.111(.185)$ & $-.011(.156)$ \\
\hline 4 & $-.064(.203)$ & $.135(.242)$ & $-.017(.158)$ \\
\hline 5 & $.024(.163)$ & $-.048(.193)$ & $.002(.141)$ \\
\hline $6+$ & $-.046(.159)$ & $.028(.128)$ & $-.010(.145)$ \\
\hline \multicolumn{4}{|l|}{ Proportion Stunted } \\
\hline 2 & $-.091(.080)$ & $-.035(.080)$ & $-.031(.076)$ \\
\hline 3 & $.040(.085)$ & $.093(.087)$ & $.067(.078)$ \\
\hline 4 & $.030(.087)$ & $-.058(.091)$ & $.037(.079)$ \\
\hline 5 & $-.073(.079)$ & $-.058(.092)$ & $-.076(.074)$ \\
\hline $6+$ & $.040(.073)$ & $-.019(.079)$ & $-.026(.070)$ \\
\hline \multicolumn{4}{|l|}{ Weight for height Z score } \\
\hline 2 & $-.152(.342)$ & -.026 (.291) & $.098(.202)$ \\
\hline 3 & $-.061(.239)$ & $.136(.272)$ & $-.044(.151)$ \\
\hline 4 & $.168(.176)$ & $.068(.224)$ & $.092(.133)$ \\
\hline 5 & $.236(.163)$ & $.189(.154)$ & $.116(.113)$ \\
\hline $6+$ & $.281(.166)^{\sim}$ & $.144(.140)$ & $.071(.113)$ \\
\hline \multicolumn{4}{|l|}{ Proportion wasted } \\
\hline 2 & $.047(.032)$ & $.041(.043)$ & $.007(.034)$ \\
\hline 3 & $-.109(.057) \sim$ & $-.001(.055)$ & $-.041(.044)$ \\
\hline 4 & $-.025(.046)$ & $.010(.040)$ & $-.018(.042)$ \\
\hline 5 & $-.032(.036)$ & $.007(.024)$ & $.002(.022)$ \\
\hline $6+$ & $-.001(.017)$ & $-.023(.028)$ & $.002(.015)$ \\
\hline \multicolumn{4}{|l|}{ Proportion with worms } \\
\hline 2 & $-.049(.067)$ & $-.204(.039)^{*}$ & $-.103(.054) \sim$ \\
\hline 3 & $.026(.072)$ & $-.117(.044)^{*}$ & $.056(.061)$ \\
\hline 4 & $.022(.080)$ & $.0005(.050)$ & $.115(.071)$ \\
\hline 5 & $.036(.075)$ & $.062(.051)$ & $.085(.045) \sim$ \\
\hline $6+$ & $.036(.075)$ & $.062(.051)$ & $.071(.070)$ \\
\hline \multicolumn{4}{|c|}{ Proportion with diarrhea in past two weeks } \\
\hline 2 & $-.179(.062)^{*}$ & $-.104(.067)$ & $-.163(.055)^{*}$ \\
\hline 3 & $-.034(.065)$ & $.013(.062)$ & $-.003(.057)$ \\
\hline 4 & $-.094(.054) \sim$ & $.027(.059)$ & $.020(.036)$ \\
\hline 5 & $-.016(.032)$ & $.001(.041)$ & $.030(.033)$ \\
\hline $6+$ & $.012(.034)$ & $.053(.028) \sim$ & $.040(.028)$ \\
\hline
\end{tabular}

Note: Standard errors in parentheses. The table contains the difference-in-difference defined as (Yp3-Yp1)(Ynp3-Ynp1), where p refers to program, np to non-program areas, and the subscripts 3 and 1 index survey round. $\sim \mathrm{p}<.10+\mathrm{p}<.05 * \mathrm{p}<.01$. 
Table D2. Estimated Intent to Treat Program Impacts by Age in Years (at Round 3) and Duration Class Using Nearest Neighbor Propensity Score Matching for Group II (Mixed or No Program Impacts) and Group III (Predominately Negative Program Impacts), Philippines ECD Study

\begin{tabular}{|c|c|c|c|}
\hline \multirow[t]{2}{*}{ Age/ECD Indicator } & \multicolumn{3}{|c|}{ Duration of Exposure (months) } \\
\hline & 4 to 12 & 13 to 16 & $17+$ \\
\hline \multicolumn{4}{|c|}{ Proportion with diarrhea } \\
\hline 2 & $-.117(.036)^{*}$ & $-.096(.034)^{*}$ & $-.189(.043)^{*}$ \\
\hline 3 & $.010(. .031)$ & $-.001(.029)$ & $-.014(.040)$ \\
\hline 4 & $-.027(.025)$ & $.076(.034)+$ & $.042(.020)+$ \\
\hline 5 & $-.003(.025)$ & $.008(.023)$ & $.003(.022)$ \\
\hline $6+$ & $-.028(.024)$ & $.006(.018)$ & $.007(.021)$ \\
\hline \multicolumn{4}{|c|}{ Proportion with worms } \\
\hline 2 & $.0005(.041)$ & $.020(.034)$ & $-.235(.037)^{*}$ \\
\hline 3 & $.017(.042)$ & $.069(.040) \sim$ & $-.148(.036)^{*}$ \\
\hline 4 & $.044(.045)$ & $.066(.050)$ & $.175(.040)^{*}$ \\
\hline 5 & $-.003(.042)$ & $.128(.048)^{*}$ & $.085(.045) \sim$ \\
\hline $6+$ & $-.066(.048)$ & $.039(.046)$ & $-.008(.041)$ \\
\hline \multicolumn{4}{|l|}{ Proportion stunted } \\
\hline 2 & $.119(.032)^{*}$ & $-.100(.044)+$ & $-.024(.051)$ \\
\hline 3 & $.115(.034)^{*}$ & $.103(.045)+$ & $.088(.037)+$ \\
\hline 4 & $.013(.027)$ & $-.014(.027)$ & $-.020(.031)$ \\
\hline 5 & $-.047(.026) \sim$ & $-.071(.030)+$ & $-.081(.034)+$ \\
\hline $6^{+}$ & $.064(.028)+$ & $-.004(.038)$ & $-.044(.029)$ \\
\hline \multicolumn{4}{|c|}{ Height for age $Z$ scores } \\
\hline 2 & $-.015(.062)$ & $-.013(.105)$ & $-.255(.118)+$ \\
\hline 3 & $.001(.064)$ & $-.081(.062)$ & $-.081(.057)$ \\
\hline 4 & $.004(.044)$ & $.028(.045)$ & $.089(.052) \sim$ \\
\hline 5 & $.062(.041)$ & $.006(.048)$ & $-.007(.039)$ \\
\hline $6+$ & $-.035(.029)$ & $.021(.035)$ & $.001(.029)$ \\
\hline \multicolumn{4}{|l|}{ Proportion anemic } \\
\hline 2 & $.189(.047)^{*}$ & $.307(.081)^{*}$ & $-.201(.116) \sim$ \\
\hline 3 & $.171(.047)^{*}$ & $.054(.045)$ & $.129(.046)^{*}$ \\
\hline 4 & $.175(.050)^{*}$ & $.084(.044) \sim$ & $.116(.046)+$ \\
\hline 5 & $.078(.048)$ & $.045(.056)$ & $.202(.047) *$ \\
\hline $6+$ & $.144(.041)^{*}$ & $.039(.045)$ & $.057(.044)$ \\
\hline \multicolumn{4}{|l|}{ Hemoglobin } \\
\hline 2 & $-.494(.121)^{*}$ & $-.686(.258)^{*}$ & $-.121(.240)$ \\
\hline 3 & $-.499(.127)^{*}$ & $.024(.116)$ & $-.430(.110)^{*}$ \\
\hline 4 & $-.471(.112)^{*}$ & $-.233(.125)^{\sim}$ & $-.266(.098)^{*}$ \\
\hline 5 & $-.190(.090)+$ & $-.170(.115)$ & $-.419(.102)^{*}$ \\
\hline $6^{+}$ & $-.228(.094)+$ & $.084(.085)$ & $-.144(.087) \sim$ \\
\hline
\end{tabular}

Note: Standard errors in parentheses. The table contains the difference-in-difference defined as (Yp3-Yp1)(Ynp3-Ynp1), where p refers to program, np to non-program areas, and the subscripts 3 and 1 index survey round. $\sim \mathrm{p}<.10+\mathrm{p}<.05 * \mathrm{p}<.01$. 


\section{6. $\quad$ References}

Alderman, Harold, Jere R. Behrman and John Hoddinott. 2005. "Nutrition, Malnutrition and Economic Growth” In Guillem López-Casasnovas, Berta Rivera and Luis Currais, eds., Health and Economic Growth: Findings and Policy Implications. Cambridge, MA: MIT Press, 169194.

Alderman, Harold, Jere R. Behrman, Hans-Peter Kohler, John A. Maluccio, and Susan Cotts Watkins. 2001a. "Attrition in Longitudinal Household Survey Data: Some Tests for Three Developing-Country Samples.” Demographic Research 5(4): 79-123.

Alderman, Harold, Jere R. Behrman, Victor Lavy and Rekha Menon. 2001b. "Child Health and School Enrollment: A Longitudinal Analysis,” Journal of Human Resources 36:1 (Winter 2001): 185-205.

Alderman, Harold, John Hoddinott, and William Kinsey. "Long Term Consequences of Early Childhood Malnutrition.” Oxford Economic Papers, forthcoming.

Baker, Amy J.L., Chaya S. Piotrkowski, and Jeanne Brooks-Gunn. 1998. “The Effects of Home Instruction Program for Preschool Youngsters (HIPPY) on Children's School Performance at the End of the Program and One Year Later.” Early Childhood Research Quarterly 13(4): 571588.

Behrman, Jere R., Yingmei Cheng and Petra Todd. 2004. "Evaluating Preschool Programs when Length of Exposure to the Program Varies: A Nonparametric Approach.” Review of Economics and Statistics 86:(1, February): 108-132.

Behrman, Jere R., and John Hoddinott. 2005. "Program Evaluation with Unobserved Heterogeneity and Selective Implementation: The Mexican Progresa Impact on Child Nutrition.” Oxford Bulletin of Economics and Statistics 67(4): 547-569.

Behrman, Jere R., Susan W. Parker and Petra E. Todd. 2006. "Long-Term Impacts of the Oportunidades Conditional Cash Transfer Program on Rural Youth in Mexico.” In Stephan Klasen and , ed., Poverty, Inequality, and Policy in Latin America. Cambridge, Mass.: MIT Press.

Behrman, Jere R., and Mark R. Rosenzweig. 2004. "Returns to Birthweight.” Review of Economics and Statistics 86 (2, May): 586-601.

Belfield, Clive R., Milagros Nores, Steve Barnett and Lawrence Schweinhart. 2006. "The High/Scope Perry Preschool Program,” Journal of Human Resources 41(1): 162-190.

Black, Robert E., Saul S. Morris, and Jennifer Bryce. 2003. "Where and Why are 10 Million Children Dying Every Year?” Lancet 361(June): 2226-2234.

Bundy, D. A. P., M.S. Chan, G.F. Medley, D. Jamison, and L. Savioli. 2001. "Intestinal Nematode Infections.” In C. J. L. Murray and A. D. Lopez, eds., The Global Epidemiology of Infectious Diseases. Cambridge: Harvard University Press.

Currie, Janet, and Duncan Thomas. 1995. “Does Head Start Make a Difference?” American Economic Review 85(3, June): 341-364.

Currie, Janet, and Duncan Thomas. 1999. "Early Test Scores, Socioeconomic Status, and Future Outcomes.” National Bureau of Economic Research Working Paper \#6943. Cambridge, Mass.

Fitzgerald, John, Peter Gottschalk, and Robert Moffitt. 1998. “An Analysis of Sample Attrition in Panel Data.” The Journal of Human Resources 33(2): 251-299. 
Frankenberg, Elizabeth, Wayan Suriastini, and Duncan Thomas. 2005. "Can Expanding Access to Basic Healthcare Improve Children's Health Status? Lessons from Indonesia's 'midwife in the village’ Programme.” Population Studies 59(1): 5-19.

Furtado, Xavier. 2001. "Decentralization and Public Health in the Philippines.” Development 44(1): 108-116.

Gertler, Paul. 2004. "Do Conditional Cash Transfers Improve Child Health? Evidence from PROGRESA’s Control Randomized Experiment,” American Economic Review 94(2): 336-341.

Glewwe, Paul, Hanan Jacoby, and Elizabeth King. 2001. "Early Childhood Nutrition and Academic Achievement: a Longitudinal Analysis.” Journal of Pubic Economics 81 (September): 345-368.

Glewwe, Paul, and Elizabeth M. King. 2001. "The Impact of Early Childhood Nutrition Status on Cognitive Achievement: Does the Timing of Malnutrition Matter?” World Bank Economic Review 15(1, May): 81-113.

Grantham-McGregor, Sally, and Cornelius Ani. 2001. "A Review of Studies on the Effect of Iron Deficiency on Cognitive Development in Children.” Journal of Nutrition 131: S649-S668.

Maluccio, John A., John Hoddinott, Jere R. Behrman, Agnes Quisumbing, Reynaldo Martorell and Aryeh D. Stein. 2005."The Impact of an Experimental Nutritional Intervention in Childhood on Education among Guatemalan Adults.” University of Pennsylvania, IFPRI, Emory, Philadelphia-Washington-Atlanta. Processed.

Martorell, Reynaldo. 1999. The Nature of Child Malnutrition and its Long-Term Implications.” Food and Nutrition Bulletin 20: 288-292.

Martorell, Reynaldo, and Teresa J. Ho. 1984. "Malnutrition, Morbidity and Mortality.” Population and Development Review 10 (Supplement: Child Survival: Strategies for Research): 49-68.

Miguel, Edward, and Michael Kremer. 2004. "Worms: Identifying Impacts on Health and Education in the Presence of Treatment Externalities.” Econometrica 72(1): 159-217.

Murnane, Richard J., John B. Willet, and Frank Levy. 1995. "The Growing Importance of Cognitive Skills in Wage Determination.” Review of Economics and Statistics 77(2, May): 251266.

Neal, Derek, and William R. Johnson. 1996. The Role of Premarket Factors in Black-White Wage Differences. Journal of Political Economy 104(5): 869-95.

Office of the Population Studies, University of San Carlos. 2002. A Study of the Effects of Early Childhood Interventions on Children's Physiological, Cognitive and Social Development (Basic Indicators Study). Cebu City, Philippines.

Office of the Population Studies, University of San Carlos. 2005. A Study of the Effects of Early Childhood Interventions on Children's Physiological, Cognitive and Social Development. Cebu City, Philippines.

Oppenheimer, Stephen J. 2001. "Iron and its Relation to Immunity and Infectious Disease.” Journal of Nutrition 131: 616S-635S.

Pollitt, Ernesto. 1997. "Iron Deficiency and Educational Deficiency. Nutrition Reviews 55(4): 133141.

Ramey, Craig T., Frances A. Campbell, and Clancy Blair. 1998. "Enhancing the Life Course for High-Risk Children.” In Jonathan Crane, ed., Social Programs that Work. New York: Russell Sage Foundation, pp. 184-199. 
Schweinhart, Lawrence J., and David P. Weikart. 1998. "High/Scope Perry Preschool Program Effects at Age Twenty-Seven.” In Jonathan Crane, ed., Social Programs that Work. New York: Russell Sage Foundation,, 148-162.

Thomas, Duncan, Elizabeth Frankenberg, and James P. Smith. 2001. "Lost But Not Forgotten: Attrition and Follow-up in the Indonesia Family Life Survey." Journal of Human Resources 36(3): 556-592.

Thomas, Duncan, Elizabeth Frankenberg, Jed Friedman, Jean-Pierre Habicht, Mohammed Hakimi, Jaswadi, Nathan Jones, Christopher McKelvey, Gretel Pelto, Bondan Sikoki, Teresa Seeman, James P. Smith, Cecep Sumantri, Wayan Suriastini, and Siswanto Wilopo. 2003. Iron Deficiency and the Well-Being of Older Adults: Early Results from a Randomized Nutrition Intervention. Los Angeles: University of California, Los Angeles, processed (version dated April 2003).

World Health Organization (WHO). 1995. Physical Status: The Use and Interpretation of Anthropometry. Technical Report Series 854. Geneva: The World Health Organization.

World Health Organization (WHO). 2001. Iron Deficiency Anaemia: Assessment, Prevention and Control. Geneva: The World Health Organization. 